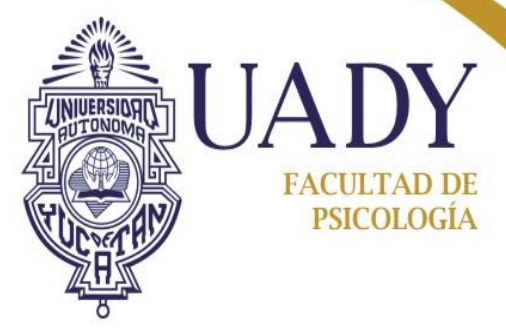

\title{
MEDICIÓN PSICOFISIOLÓGICA: ANALISIS DE ESTRÉS DE VOZ EN CREDIBILIDAD DE TESTIMONIO EN INTERNOS DEL CE.RE.SO. DE TEKAX, YUCATÁN
}

\section{TESIS}

QUE PARA OBTENER EL TÍTULO DE LICENCIADO EN PSICOLOGÍA

PRESENTA

Br. JOSÉ LUIS CHI ZALDÍVAR

\author{
ASESOR \\ MTRO. JOSÉ PAULINO DZIB AGUILAR
}

MÉRIDA, YUCATÁN, MÉXICO

JUNIO DE 2012 
Medición Psicofisiológica en Credibilidad de Testimonio II

\section{Dedicatoria}

A mi abuelo que fue un padre para mí Y que ya no se encuentra conmigo, Le dedico este la presente tesis Como fruto de la educación Y de todas las enseñanzas que me dejó 
Agradecimientos

Agradezco antes que a nadie, a mi madre porque es la persona por la cual me encuentro aquí en este mundo y he llegado tan lejos, ella hizo su mayor esfuerzo para que me convirtiera en un hombre de bien y se esforzó para darme la oportunidad de estudiar una carrera. Le agradezco todo su empeño y tenacidad para ayudarme a cumplir mis sueños y terminar satisfactoriamente con esta etapa de mi vida y espero poder retribuirle todo lo que me ha dado con creces.

A una persona muy especial, que estuvo conmigo en buenas y malas, y siempre estuvo ahí para brindarme consejo o palabras de aliento cuando las cosas parecían muy difíciles y sentía que ya no podía más, a esa persona le agradezco de todo corazón todo su apoyo, porque sin ella no sería la persona que soy ahora.

A mis asesor de tesis, profesor y mentor, el Maestro José Paulino Dzib Aguilar por brindarme su consejo y asesoría en la realización de este proyecto. A la Maestra Verónica Godoy Cervera directora técnica del proyecto PRIORI que me brindo toda su ayuda y apoyo para culminar con esta tesis y que estuvo al pendiente del proceso de realización de la misma.

Por último a mis compañeros y compañeras del Centro de Investigación en Psicología Forense para Menores (CIPFoM), que colaboraron conmigo en este proyecto y que fueron de gran ayuda en diferentes momentos de la realización de esta tesis, les agradezco su solidaridad y compañía. En especial a mi compañera Carolina que me brindo su ayuda para realizar el experimento y me acompaño en los viajes al CE.RE.SO. Ella es en gran parte la razón de que esta tesis exista. 
Medición Psicofisiológica en Credibilidad de Testimonio IV

Declaro que esta tesis es mi propio trabajo, a excepción de las citas en las que se ha dado crédito a los autores; asimismo, que este trabajo no ha sido presentado previamente para la obtención del algún otro título profesional o equivalente. 


\section{Contenido}

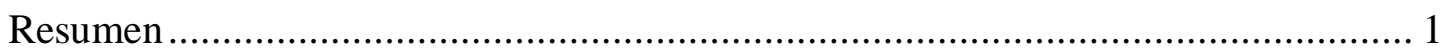

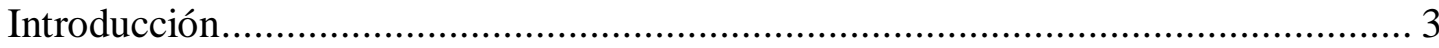

Descripción del Problema ……………………………................................... 5

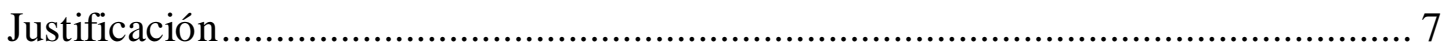

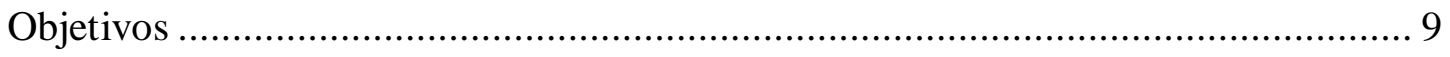

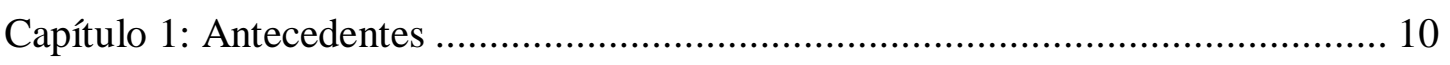

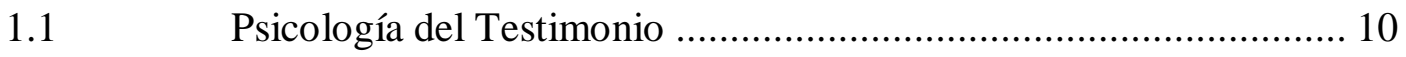

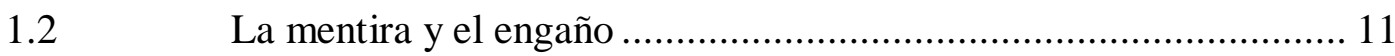

$1.3 \quad$ Credibilidad de Testimonio ......................................................... 12

1.5 Instrumentos de Evaluación en Credibilidad de Testimonio ............. 14

1.6 Instrumentos de evaluación en procesos jurídicos ............................ 16

$1.7 \quad$ Psicofisiología de las emociones ................................................. 17

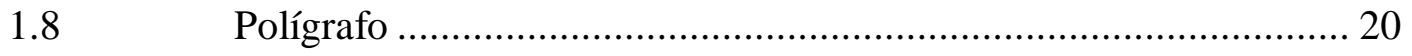

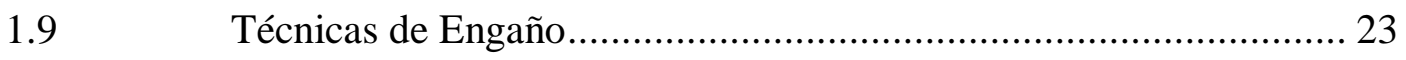

1.9.1. Técnica de preguntas Relevantes e Irrelevantes: ......................... 26

1.9.2. Técnica de Pregunta Control: ..................................................... 27

1.9.3. Técnica de pregunta de Mentira Directa: .................................... 28

1.9.4. Técnicas de Información o Pico de Tensión: ................................ 28

1.9.5. Técnica de Tensión Máxima o Solución Conocida: ...................... 29

1.9.6. Técnica de Conocimiento Oculto o Búsqueda: ............................. 29

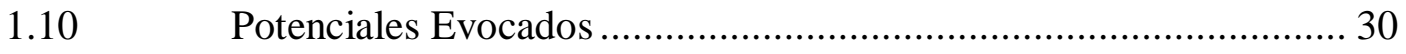

$1.11 \quad$ Analizadores de Estrés de Voz ..................................................... 31 
1.12 Inventario Clínico Multiaxial de Millon-III .................................... 38

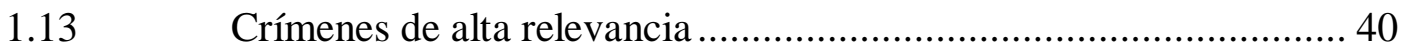

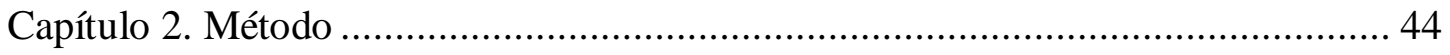

2.1. Preguntas de Investigación ............................................................. 44

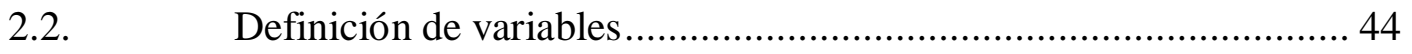

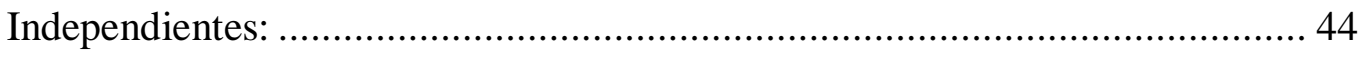

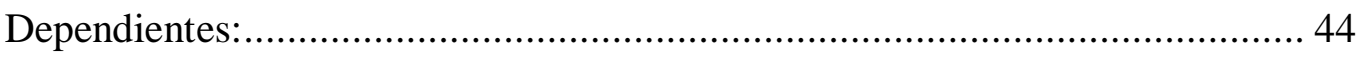

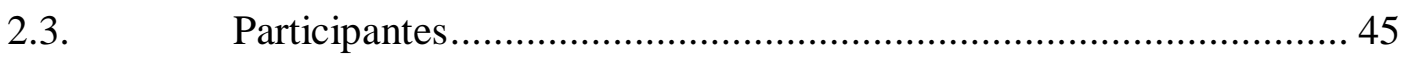

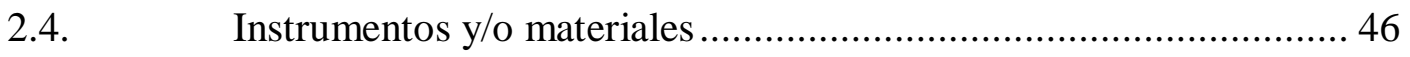

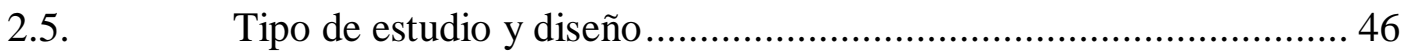

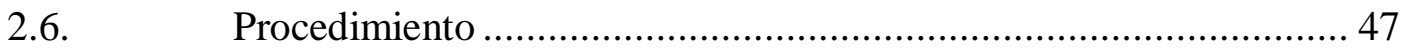

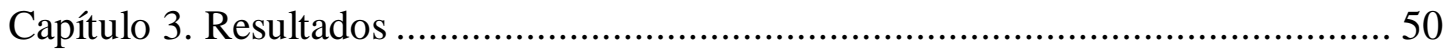

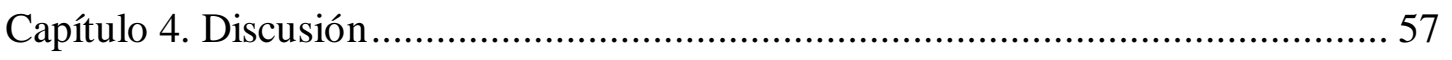

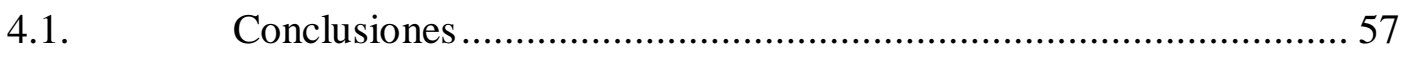

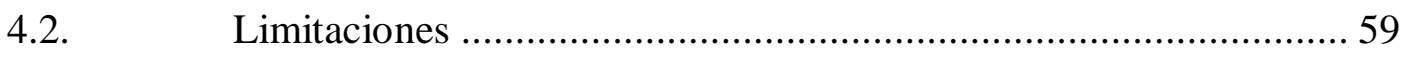

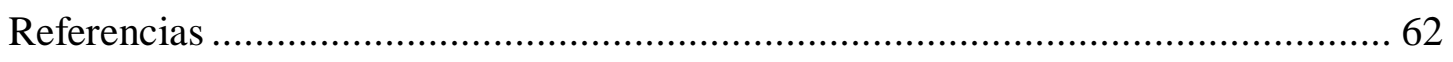

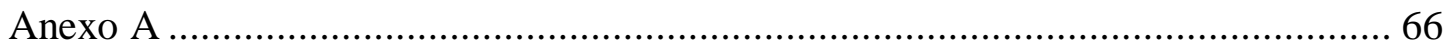

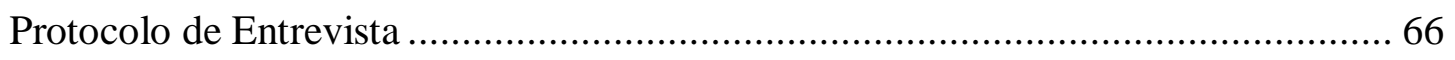

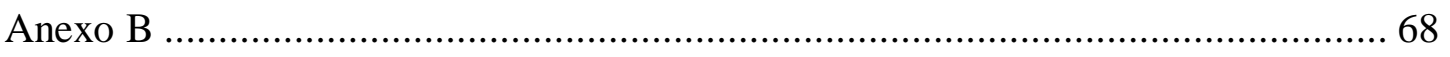

TARJETAS DE INSTRUCCIONES PARA EXPERIMENTO_.................................. 68 
Medición Psicofisiológica en Credibilidad de Testimonio VII

\author{
Índice de Tablas
}

Tabla 1: Cambios fisiológicos en las principales emociones...................................... 19

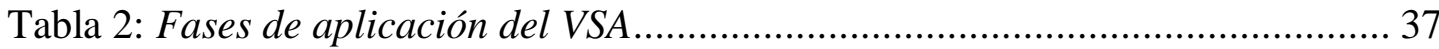

Tabla 3: Frecuencias y porcentajes de delitos ........................................................ 42

Tabla 4: Medias por tipos de delitos de las escalas del Millon-III ............................. 53

Tabla 5: Escalas con altos puntajes en las medias del MCMI-III............................... 55

Tabla 6: Resultado del Experimento y puntajes T de las Escalas altas de la muestra. 
Medición Psicofisiológica en Credibilidad de Testimonio VIII

\author{
Índice de Figuras
}

Figura 1: Grafico de Barras de Porcentajes de Delitos en el CE.RE.SO. de Tekax .. 43

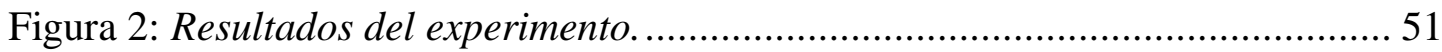

Figura 3: Porcentajes de identificados correctamente/incorrectamente. .................... 52 


\section{Resumen}

En el presente trabajo se empleó el equipo de Análisis de Estrés de Voz (VSA; por sus siglas en ingles) para la evaluación de la credibilidad de testimonio en una muestra de 24 internos del Centro de Reinserción Social de Tekax, Yucatán; los cuales se encuentran internados por haber cometido uno de los siguientes delitos: violación, homicidio y robo.

El diseño de este estudio fue cuasi-experimental con ciego simple. Se dividió a los participantes en un grupo experimental y un grupo control. Se aplicó una entrevista de tipo Control Question Test usando el equipo Digital Voice Stress Analyzer (DVSA) para registrar las respuestas antes las preguntas del cuestionario (Damphouse, Pointon, Upchurch, Moore, 2007) y posteriormente evaluar la credibilidad de los sujetos en las respuestas que dieron. Después un investigador que participó en ninguna fase anterior del estudio, interpretó los resultados obtenidos del DVSA e hizo la evaluación de credibilidad de las respuestas de los sujetos identificándolos como Deshonestos o No Deshonestos. Por último se cotejó las interpretaciones realizadas con las instrucciones dadas a cada participante.

Del total de la muestra, 24 sujetos, 11 pertenecían al grupo experimental y 12 al grupo control, ocho sujetos habían cometido el delito de robo, ocho sujetos el delito de violación y ocho sujetos el delito de homicidio (uno de los participantes en la categoría de homicidio, no quedo dentro de la muestra utilizable pues aun cuando siguió las instrucciones correctamente la grabación de la entrevista no se hizo correctamente)

Se encontró que un mayor porcentaje de la población (34.8\%) fue catalogada correctamente como No Deshonestos; $26.1 \%$ de la población fue catalogada correctamente como Deshonestos; otro $21.7 \%$ de la población fue catalogada incorrectamente como No Deshonestos, por último $17.4 \%$ de la población fue identificada incorrectamente como Deshonestos. El porcentaje total de la población identificada correctamente ya sea como honestos o deshonestos fue el 60.87\%, 
mientras que un $39.13 \%$ de la población fue identificada incorrectamente como honesto o deshonesto.

Se concluye que más de la mitad de las interpretaciones sobre la honestidad o deshonestidad de las respuestas fueron acertadas, identificando correctamente a los sujetos cuando respondían con la verdad o mintiendo.

Para finalizar no se encontró relación entre las puntuaciones obtenidas en las escalas: Narcisismo, Deseabilidad Social y Paranoide del Millon-III con los resultados de las evaluaciones de credibilidad, el porcentaje de sujetos evaluados correctamente, Verdaderos positivos o falsos, fue de $57.15 \%$ y el porcentaje de sujetos evaluados incorrectamente como Falsos positivos o Falsos Negativos fue del 42.85\%; se puede concluir que el uso del VSA para analizar la credibilidad de testimonio con personas con características de personalidad Paranoide, Narcisista o de alta Deseabilidad Social tendrá resultados confiables, se puede concluir que estas características de personalidad en hombres internos no afectan la eficacia del equipo para identificar correctamente cuando los individuos son honestos o deshonestos en sus respuestas. 


\section{Introducción}

El presente trabajo de tesis tiene como finalidad el explorar la eficacia de la tecnología del Análisis de Estrés de Voz (VSA por sus siglas en inglés) como una herramienta útil para la detección del engaño al momento de realizar evaluaciones de la Credibilidad del Testimonio.

Está comprobado que el estrés y la emoción intensa se manifiesta a través del aumento en la actividad fisiológica general, que es más acusada en el sistema nervioso vegetativo y en las funciones corporales que dependen de él. (Martínez, 2005). También señala que en estudios relacionados a la mentira se estudian los cambios en la presión arterial, las frecuencias cardiaca y respiratoria y los cambios en la actividad eléctrica de la piel asociados a la sudoración ya que se sabe que ciertas variables de personalidad podrían afectar las mediciones psicofisiológicas

Es conocida la teoría de que los psicópatas o personas con algún trastorno de personalidad poseen una gran facilidad para decir mentiras sin sentir remordimiento, culpa o miedo al castigo; estas cualidades se ven reflejadas en las psicofisiología del individuo, una persona sin miedo a ser castigada por mentir, que no tiene remordimiento por hacerlo o que simplemente no puede entender que el mentir es considerado como algo malo por la sociedad, no reflejará los cambios psicofisiológicos relacionados al proceso de mentir, como los son: el aumento del ritmo cardiaco o un incremento en la transmisión galvánica de la piel (Raskin \& Hare, 1978); y en el caso de del VSA no experimentará los cambios en los músculos de las cuerdas vocales (microtemblores), los cuales están asociados al proceso de mentir o dicho de otro modo cuando una persona da una respuesta deshonesta a una pregunta. Estos microtemblores son detectados por la tecnología VSA y representados en forma de gráficas y después se interpretan los resultados de cada pregunta siguiendo un procedimiento descrito más adelante en el texto y por último se categoriza a la persona como Deshonesto o No Deshonesto. Esta categorización evita usar términos como verdad o mentira, ya que estos conceptos son términos absolutos que implican un riesgo elevado en procesos de Credibilidad de Testimonio. No se encontraron 
investigaciones que relacionen el uso del VSA en individuos con algún trastorno de personalidad o con psicopatía, aun cuando el uso de los equipos de VSA tienen cerca de 30 años de existencia, por eso en esta tesis se tratara de encontrar alguna correlación entre la eficacia del uso del DVSA para detectar correctamente personas honestas y deshonestas y los trastornos de personalidad encontrados en los participantes. 


\section{Descripción del Problema}

La búsqueda de la verdad, es una de las mayores problemáticas a las que se enfrenta el sistema de justicia; ¿cómo saber que paso en un crimen?, ¿cómo estar seguros que un testigo, víctima o victimario son honestos al narrar los hechos o al responder a las interrogantes de los agentes de la ley o responden velando por intereses personales? Estos desafíos dieron como resultado que la justicia trate de encontrar formas para verificar si un testimonio es veraz o creíble, en especial cuando no se tienen otro tipo de pruebas para corroborar lo que paso en realidad.

A lo largo de los años se han empleado una gran cantidad de métodos y técnicas para este fin, de ahí surgieron los procedimientos psicofisiológicos como el polígrafo, los cuales aclaman tener un alto nivel de certeza y un amplio sustento científico y metodológico que los respalda y afirman ser la mejor herramienta para evaluar la credibilidad de testimonio de una persona. El polígrafo lleva más de cien años como medio de evaluación de la credibilidad y ha pasado por un sinfín de investigaciones y pruebas para medir su certeza y confiabilidad; con menos tiempo en la escena, poco más de 30 años los analizadores de estrés de voz han aparecido como una alternativa al uso del polígrafo y argumentando ser menos invasivos, más rápidos y más certeros en la evaluación de la credibilidad de testimonio.

En el presente trabajo de investigación se abordó y analizó la medición psicofisiológica de la voz para comprobar su eficacia y utilidad durante la evaluación de la credibilidad del testimonio. Esta medición se realizó en una población de internos del Centro de Reinserción Social de Tekax, Yucatán, los cuales están internados por haber cometido alguno de estos tres delitos robo, homicidio o violación. De esta forma se pretende recabar información acerca de cómo esta técnica, refiriéndose al Análisis de Estrés de Voz; puede resultar útil para el esclarecimiento de la credibilidad y sus componentes.

Se pretende analizar si el uso de este instrumento fisiológico es de utilidad para discernir cuando una persona está siendo honesta o deshonesta en sus respuestas, dada una situación particular. ¿Será que esta técnica es eficaz para detectar cuando 
una persona es deshonesta $u$ honesta en sus respuestas y si estos pueden servir como un instrumento que facilite los procesos de evaluación de la credibilidad?

Si este tipo de instrumentos resultan ser eficaces para detectar cuando una persona es honesta o deshonesta en sus respuestas aportaría una mayor cantidad de herramientas para el trabajo de los profesionistas relacionados en procesos judiciales, como abogados, psicólogos, peritos, policías, jueces, etc., dentro de los procesos de evaluación de la credibilidad de testimonio.

Aun cuando el uso del polígrafo está bastante extendido en México en procesos de evaluación de la credibilidad de testimonio y en procesos de control de confianza, la ciencia debe preocuparse por descubrir y desarrollar nuevas tecnologías y herramientas para llegar a un análisis más eficaz de la credibilidad; y no depender de un solo tipo de herramienta o estrategia para el mismo proceso.

También se busca encontrar si existe alguna correlación entre las variables de personalidad y los resultados que arroje el DVSA respecto a la evaluación de la credibilidad de testimonio. Explorar si alguna variable de personalidad, tiene un efecto adverso sobre la fisiología del individuo y esto por lo tanto contamina el proceso de evaluación y análisis del estrés de la voz registradas por el DVSA. Es importante señalar que un estado psicofisiológico alterado imposibilita el uso de equipos psicofisiológicos para la detección del engaño, pues no se puede tener certeza en que lo registrado por los equipos sea información confiable. Es posible que una variable de personalidad, por sus características psicológicas no se vea afectado por el proceso de evaluación y no sienta temor de ser descubierto mintiendo y esto se refleje en un bajo nivel de estrés de la voz. Lo cual conllevaría a anular la supuesta eficacia del DVSA para detectar cuando una persona es honesta o deshonesta. 


\section{Justificación}

El fenómeno de mentir está proscrito en todas las culturas y se han realizado grandes esfuerzos para intentar superarlo. Esto no se debe a que a la gente le disguste ser engañada sino que la mentira puede llegar a ser una amenaza a la estabilidad de la sociedad. El engaño no es un estado normal de la mente, no es un sentimiento y por lo tanto no puede ser tratado como tal. La emoción relacionada con el engaño está fuertemente relacionada con la causa; cuando uno no está diciendo la verdad se detectará un elevado nivel del estado emocional (Benavides, 2007).

En los diferentes ámbitos del ejercicio profesional del psicólogo, el disimulo, el encubrimiento, la exageración, el filtrado y el falseo de la información suministrada o la negación de problemas son fenómenos muy frecuentes y constituyen un importante obstáculo a la hora de realizar una correcta evaluación de cada caso y de tomar decisiones legales- (Lemos, 2005).

El análisis de la credibilidad de testimonio en los ámbitos judiciales o policiales cobra una gran importancia pues la búsqueda de la verdad conlleva un análisis riguroso y metódico para saber con certeza cuando una persona está siendo honesta o deshonesta en un proceso judicial, por eso es importante realizar estudios científicos que posean una metodología rigurosa para evaluar la eficacia de los equipos psicofisiológicos en la detección del engaño y la evaluación de la credibilidad.

El estudio e investigación de los instrumentos psicofisiológicos, para verificar su validez y rigor científico son de vital importancia para saber a ciencia cierta si estos equipos pueden generar una nueva área de conocimiento que sea usada dentro de las áreas jurídicas, penales y forenses, y aportar información útil y diferente para determinar si estos instrumentos son o no eficaces como herramientas en las investigaciones policiacas para detectar la deshonestidad en evaluaciones de credibilidad de testimonio. Está área de estudio guarda una fuerte relación con la psicología, ya que el análisis de la credibilidad de testimonio y su relación con diferentes variables psicofisiológicas son fenómenos propensos al estudio de 
psicólogos, igualmente muchos de los ámbitos o áreas en las que son usados, como la criminología, las ciencias forenses y la ciencias penales son afines a la psicología.

En México no se conocen datos o investigaciones realizadas con equipo de análisis de estrés de voz, tampoco hay investigaciones que se hayan llevado a cabo con población mexicana y mucho menos realizadas con población penitenciaria. Este estudio brinda una oportunidad de explorar el funcionamiento de equipos psicofisiológicos como herramienta para la evaluación de la credibilidad de testimonio en una población con características que los convierten en objetivos de este tipo de evaluaciones.

Como conclusión se puede afirmar que es importante explorar como estas nuevas tecnologías y equipos pueden brindar una gran ayuda a ciertas disciplinas de la psicología, como la psicología criminológica e igualmente, generar una mayor cantidad de conocimientos útiles al campo científico. También se deben vincular los conocimientos que aporta la ciencia psicológica con ámbitos de aplicación específicos, como lo es el VSA, los cuales son poco usados o poco desarrollados en el estado de Yucatán y de esta manera se asegurar la creación de nuevos nichos de trabajo para los profesionistas de la psicología, y desarrollar nuevos conocimientos para la ciencias psicológicas. 


\section{Objetivos}

- Comprobar la eficacia (porcentaje de éxito para detectar correctamente a las personas que son honestas o deshonestas) del uso del software DVSA para la detección del engaño en procesos de credibilidad de testimonio.

- Describir la relación entre los resultados de las evaluaciones de credibilidad y las características de personalidad de los sujetos. 


\section{Capítulo 1: Antecedentes}

\subsection{Psicología del Testimonio}

La prueba testifical en sus diferentes expresiones (descripciones e identificaciones) es uno de los pilares probatorios en los distintos procesos judiciales, resultando de especial importancia en los procesos penales. Los tópicos sobre los que ha versado mayoritariamente la investigación dentro de la Psicología del Testimonio han sido cuatro (Manzanero, 2008)

a) Los factores de influencia en la exactitud de los testimonios, ya que los testimonios pueden ser imprecisos atendiendo a distintos factores que pueden incidir en el proceso de codificación, almacenamiento y recuperación del recuerdo.

b) Los procedimientos de obtención de declaraciones que permitan obtener la mayor cantidad posible de información exacta, sin influencias negativas.

c) La evaluación de la credibilidad del testimonio, ya que constituye una demanda histórica por parte del Derecho a la Psicología la elaboración de métodos de detección de testimonios falsos (por engaño o error)

d) Las pruebas de identificación realizadas por testigos y la evaluación de su exactitud, que ayudarían a evitar, o al menos minimizar, algunos de los errores que se cometen y a valorar adecuadamente la actuación de los testigos (Manzanero, 2008).

Así, la investigación en Psicología del Testimonio tiene dos claras aplicaciones profesionales que entroncan con algunas de las especialidades descritas anteriormente: por un lado, para el psicólogo criminalista (aplicaciones de técnicas de entrevista para el interrogatorio policial, elaboración de retratos robots 0 reconocimiento de sospechosos) y por otro, para el psicólogo forense (facilitar la toma de declaraciones de las partes y asesorar a los tribunales para una mejor valoración de la prueba testifical).

La investigación en la psicología del testimonio comenzó en los últimos años del siglo XIX y comienzos del siglo XX. La obra de Münsterberg "On the witness" stand determinó el origen de la psicología del testimonio, en la que señala la 
necesidad de una reforma legal basada en la experimentación científica, ya que el testimonio de un testigo, aun actuando de buena fe, puede ser erróneo. (Ibabe, 2000)

Posteriormente Stern $(1910,1913)$ analizó los errores cometidos por niños en el recuerdo libre y en las formas interrogativas, junto con los efectos de la sugestión debido al interrogatorio sobre la memoria del suceso. (Ibabe, 2000)

\subsection{La mentira y el engaño}

La mentira es la expresión manifiesta contraria a lo que se sabe, se cree o se piensa. Engañar es dar a la mentira apariencia de verdad o inducir a alguien a tener por cierto lo que no es, valiéndose de palabras y de obras aparentes o fingidas. Mientras que la mentira se refiere así al contenido de un mensaje que refleja adecuadamente o no la realidad, el engaño, o la acción de engañar, incluye el concepto clave de intencionalidad o voluntariedad. (Martínez, 2005). Se dice que una persona miente cuando deliberadamente aporta una información de la que sabe conscientemente que no se ajusta a la realidad de los hechos (Massip, Garrido y Herrero, 2004 en Manzanero, 2008)

El engaño no es exclusivo de la especie humana sino que es también una característica que está presente en los primates y en otros animales que viven en entornos sociales de gran complejidad; y en los reinos animal y vegetal son numerosos los seres vivos que han desarrollado, en el proceso evolutivo, capacidades

de camuflaje y de adaptación muy elaboradas, que han prosperado gracias al efecto de confundir a sus competidores o a sus depredadores. (Lemos, 2005)

Como se mencionó anteriormente el fenómeno de mentir está proscrito en todas las culturas y se han realizado grandes esfuerzos en intentar superarlo pues amenaza el bienestar la sociedad (Benavides, 2007). Si una persona es creíble y fiable, los demás tenderán a creer lo que se dice y podrán ser convencidos. El mentiroso intentará reforzar a toda costa su credibilidad y utilizarla para que la crean (Martínez, 2005) 
Frecuentemente, la credibilidad es una cuestión de percepción, de que alguien sea percibido como una persona fiable; el mentiroso intentará dar una imagen creíble positiva y honesta de sí mismo.

Manzanero (2008) afirma que el desarrollo de procedimientos para discriminar a las personas que mienten en sus declaraciones se remonta al inicio de los sistemas de administración de justicia. Así, podemos encontrar referencias a diferentes métodos para detectar la mentira en escritos Vedas en la India de hace 3000 años, donde se propone la observación de las respuestas no verbales de los sospechosos como técnica. Mientras en occidente, el médico griego Erasistratus (300-250 a. c.), al servicio de Alejandro El Grande, propuso medir algunas respuestas fisiológicas.

El engaño es "un intento deliberado exitoso o no, que se hace sin aviso, para crear en otro una creencia el cual el comunicador considera no ser verdadera" (Vrij, 2000). El engaño es un acto intencional. El engaño se define únicamente desde la perspectiva del que engaña y no si la declaración es factual, un tercer aspecto del engaño es que las personas solo mienten cuando ellos no informan a otros de sus intenciones de mentir.

\subsection{Credibilidad de Testimonio}

Ya se ha hablado de la mentira y como está a coexistido con las personas desde tiempos muy remotos, es por esa razón que desde que la mentira ha existido el hombre ha buscado maneras para poder desenmascararla y encontrar la verdad, en este intento del hombre por hallar la verdad objetiva de las cosas, esté ha desarrollado diferentes maneras para encontrarla, unas con un carácter más científico que otras. Este desarrollo de los procedimientos para discriminar a las personas que mienten en sus declaraciones se remonta al inicio de los sistemas de administración de justicia.

En Garrido, E., Masip, J. \& Herrero, M. C. (2006) se mencionan las prácticas de la edad media, en la que se establecía un combate judicial entre dos partes en disputa para determinar quién estaba en posesión de la verdad. También se recurría a las ordalías, que consistían en peligrosas pruebas tales como andar cierta distancia 
sosteniendo un hierro candente en las manos, si el acusado salía indemne de estas pruebas, su inocencia quedaba demostrada, la explicación que se daba aludía a la intervención divina.

Podemos definir la credibilidad como la valoración subjetiva de la exactitud estimada de las declaraciones de un testigo. Esta valoración se basa en inferencias que consideran diferentes aspectos como las circunstancias y características del delito, nuestros conocimientos y creencias, y la congruencia estimada entre las declaraciones y otros elementos de prueba (Manzanero y Diges, 1993 en Manzanero, 2008). No se trata de determinar, si un testigo en su personalidad tiende a hacer declaraciones falsas, o quizás, si ya lo ha hecho. También un mentiroso empedernido puede hacer, en un caso específico, declaraciones creíbles. Mucho más se trata de determinar, si los sucesos descritos en la declaración corresponden a hechos realmente vividos (Heinz, O. 2000).

Es importante diferenciar entre dos factores importantes al estudiar la credibilidad, una es la competencia, la cual es la habilidad del interrogado para decir la verdad (aspecto cognitivo), y la segunda es la credibilidad, esto es, la voluntad del mismo para expresar esta verdad (aspecto motivacional). (Lamb et al. 1994, en Garrido, Masip, 2000).

En general el estudio del engaño y su detección puede estructurarse dentro de tres perspectivas generales: la psicofisiológica, la de los indicadores verbales de la mentira, y la de los indicadores no-verbales o conductuales del engaño. (Garrido \& Masip, 2000; Garrido, E., Masip, J. \& Herrero, M. C., 2006; Manzanero, 2008). La aproximación verbal y psicofisiológica han desarrollado instrumentos $\mathrm{y}$ procedimientos sistematizados para la detección del engaño, cuya fiabilidad y validez pueden ser examinadas. (Garrido, et al. 2006)

En Garrido y Massip (2000) se abordan diferentes teorías que explican porque el mentir o engañar ocasiona una elevada carga cognitiva y fisiológica para la persona, la primera es la Teoría de la Respuesta Condicionada, la cual asume que una mentira actual evoca respuestas autónomas porque la pregunta que da lugar a dicha mentira fue condicionada a una experiencia de deshonestidad y, por lo tanto, 
traumática; también es posible que no sea la pregunta la que evoca la mentira presente, sino la misma mentira, la que se vio condicionada en el pasado al hecho de mentir, el cual, en ocasiones, dio lugar a consecuencias displacenteras. Una segunda teoría es la Teoría del Conflicto, esta afirma que la elevada responsabilidad asociada a la mentira es una consecuencia de tendencias opuestas, a decir la verdad y mentir, las cuales entran en conflicto. Por último la Teoría del Castigo atribuye el arousal que suele acompañar al acto de mentir a la anticipación del castigo si la mentira se descubre, lo que nos recuerda al miedo a ser descubierto de Ekman. Su sentimiento de culpa por mentir podría también dar lugar a la activación psicofisiológica.

\subsection{Instrumentos de Evaluación en Credibilidad de Testimonio}

Ante la necesidad de crear instrumentos eficaces para evaluar la credibilidad de testimonio varios investigadores se han centrado en el desarrollo de métodos sistemáticos que ayuden a identificar informes honestos de aquellos informes que han sido fabricados. Vrij (2000) y Vrij, Edward y Bull (2001) han clasificado estos procedimientos en tres grupos. El primero se centra en el registro y análisis de la actividad psicofisiológica de la persona que miente. El segundo se encarga de examinar la conducta no verbal del sujeto (Vrij, Edward, Roberts y Bull, 2000). El tercer grupo, se encarga del estudio del contenido de la declaración del testigo (Masip, Sporer, Garrido y Herrero, 2005; Ruby y Brigham, 1997).

En este apartado se mencionarán algunas técnicas utilizadas para evaluar la credibilidad de testimonio. El primero a mencionar es el Sistema de Análisis de la Validez de las declaraciones (SVA), este es un método usado en el ámbito forense y que tiene un amplio uso para asesorar en la credibilidad de testimonio infantil. (Vázquez, 2007). Este sistema también usa el Análisis de Contenido Basado en Criterios (CBCA) para corroborar la credibilidad del discurso del menor. Ambas técnicas fueron diseñadas originalmente para ser usados en la declaración de 
menores, pero en la actualidad su uso se ha generalizado en personas de todas las edades.

A grandes rasgos el SVA incluye los siguientes pasos:

a) Una entrevista que no sesgue las respuestas del menor.

b) Aplicar a la transcripción de la entrevista los 19 criterios del CBCA.

El CBCA fue creado por Udo Undeustch, al sugerir que al entrevistar al testigo fuera de la atmosfera judicial, grabar la entrevista y luego analizarla. Undeustch fue el primero en resaltar que las declaraciones basadas en algo ocurrido realmente diferían de aquellas fruto de la imaginación ("hipótesis de Undeustch) (Vázquez, 2007)

El CBCA se divide en 19 criterios agrupados en 5 categorías:

a) Características generales
a. Estructura lógica
b. Elaboración no estructurada
c. Cantidad de detalles

b) Contenidos específicos
a. Incardinación en contexto
b. Descripción de interacciones
c. Reproducción de conversaciones
d. Compilaciones inesperadas durante el incidente

c) Peculiaridades del contenido
a. Detalles inusuales
b. Detalles superfluos
c. Incomprensión de detalles sexuales relatados con precisión
d. Asociaciones externas relacionadas
e. Alusiones al estado mental subjetivo del menor
f. Atribuciones al estado mental del agresor
d) Contenidos relacionados con la motivación
a. Correcciones espontaneas
b. Admisión de falta de memoria
c. Dudas sobre el propio testimonio 


\section{d. Autodesaprobación \\ e. Perdón al agresor}

e) Elementos específicos de la agresión.

\subsection{Instrumentos de evaluación en procesos jurídicos}

Los procesos de evaluación en los procesos jurídicos se han diversificado notablemente en el transcurso de los años, en la actualidad consta de diferentes pasos a seguir, como lo son: la entrevista o interrogatorio, la aplicación de pruebas psicométricas, listas de chequeo (checklists) y el uso de técnicas psicofisiologicas.

El interrogatorio o entrevista es un encuentro hablado entre dos personas que comporta tanto interacciones tanto verbales como no verbales, y en la que una de las personas pide información y la otra se la brinda. (Jiménez, 2006).

También existen entrevistas estructuradas, normalmente no estandarizadas, para valorar temáticas forenses como actitudes facilitadoras de violencia, actitudes educadoras en los padres, investigación de abuso sexual infantil, valoración del trastorno de estrés postraumático, valoración neuropsicológica, evaluación del toxicómano, del agresor sexual, etc. (Vázquez, 2007).

Dentro de las ventajas de este instrumento se encuentran: a) la posibilidad de observación del comportamiento del entrevistado, b) la posibilidad de registrar grandes cantidades de información y c) la flexibilidad del instrumento para poder adaptarse a la situación. Pero entre las desventajas o limitaciones de este instrumento están en el costo relativamente elevado en cuanto al tiempo y esfuerzo del entrevistador. (Jiménez, 2006).

Las listas de verificación, listas de chequeo o checklists son al igual que los instrumentos y técnicas ya mencionadas, herramientas de amplio uso en el ámbito jurídico, son un modo relativamente sencillo, económico y bastante confiable para describir o evaluar a una persona. Consiste en una lista de palabras, frases, o afirmaciones descriptivas de una persona o algún objeto o acontecimiento. Se 
elaboran con mayor facilidad que una escala de calificación o inventario de personalidad, y a menudo poseen igual validez, se pueden aplicar como instrumento de autorreporte o de informe de un observador. (Aiken, 2003).

Entre las listas de verificación más usadas se encuentran: la Lista de Verificación de Adjetivos (ACL); Lista de Verificación de Adjetivos de Afecto; Lista de Verificación de Adjetivos para la Depresión Estado-Rasgo (ST-DACL); Lista de Verificación de problemas; Lista de Verificación de la Conducta Infantil; Lista de Verificación de Problemas de Conducta (RBPC); Lista de Verificación de Síntomas; PCL-R, entre otras. (Aiken, 2003).

Otros instrumentos de amplio uso en los procesos jurídicos son las pruebas psicométricas, las cuales son pruebas de lápiz y papel que exploran diferentes áreas del individuo, por ejemplo: patologías, inteligencia, personalidad, etc.; dentro del amplio rango de pruebas psicométricas utilizadas se pueden encontrar las siguientes: el cuestionario factorial de personalidad de Catell (16 PF); el Inventario Multifásico de Personalidad de Minnesota (MMPI) y el Inventario Clínico Mental de Millon (MCMI I y II). (Jiménez, 2006).

Ahora bien, abordando el tema de interés de la presente investigación, el uso de las pruebas fisiológicas tiene sus orígenes en Italia en el siglo XIX iniciado por Lombroso. Reportándolo como instrumento de veracidad (Raskin, 1994). La expansión del estudio y aplicación del polígrafo se ha dado en diferentes continentes; dejando a su paso dos características básicas la esperanza de poder acercarse al conocimiento de si una persona miente o dice la verdad y la polémica de la validez y confiabilidad de los resultados obtenidos por la aplicación de la técnica. (Jiménez, 2006).

\subsection{Psicofisiología de las emociones}

En primer término es importante definir el concepto de emociones, entendidas como las reacciones complejas y estructuradas, de carácter rápido, difícil de 
controlar, con un fuerte contenido subjetivo y fisiológico, que alteran el comportamiento que se está realizando en ese momento (Martínez Selva, 1995).

Para hablar de emociones es importante que se cumplan tres características básicas: el componente comportamental, el hecho de que es algo automático y difícil de controlar y por último el componente hormonal. Normalmente el factor más notable a simple vista es el comportamental, pero lo que tiene que ocurrir para que se de algún comportamiento es que algún estímulo del exterior, active el componente hormonal el cual facilita la activación de las respuestas neurovegetativas, lo que lleva a una respuesta comportamental. (Carlson, 2000).

Para conocer las funciones vegetativas que propician cambios comportamentales se propone la siguiente lista: cambios en la electricidad de la piel, velocidad cardiaca, nivel de presión sanguínea, vasoconstricción y vasodilatación, cambios en la velocidad, amplitud y regularidad de la respiración, temperatura de la piel, sudoración, alteraciones en el diámetro de la pupila, cambios en el funcionamiento digestivo, contracción o relajación de los esfínteres, variaciones en la electricidad del cerebro, cambios en la química de la sangre, de la orina y de la saliva, y alteraciones del metabolismo basal. Es importante tener en cuenta que todas estas funciones no se tienen que presentar al mismo tiempo ni en todas las emociones, si no que esto varía según la persona y la emoción experimentada al momento. (Fraisse (1963) en Godoy-Cervera \& Dzib-Aguilar, 2010)

El estrés y la emoción intensos se manifiestan a través del aumento en la actividad fisiológica general, que es más acusada en el sistema nervioso vegetativo y en las funciones corporales que dependen de él. Principalmente se estudian los cambios en la presión arterial, las frecuencias cardiaca y respiratoria y los cambios en la actividad eléctrica de la piel asociados a la sudoración. (Martínez, 2005) 
Tabla 1: Cambios fisiológicos en las principales emociones.

\begin{tabular}{ll}
\hline Emoción & Cambios fisiológicos \\
\hline Miedo & Aumento en la frecuencia cardiaca, aumento en la presión arterial \\
& sistólica, disminuye la temperatura cutánea digital y cefálica. \\
& Disminuyen los niveles de conductancia cutánea, aumentan los niveles \\
& de conductancia cutánea, aumenta el tono muscular general, respiración \\
& superficial y frecuencia respiratoria irregular. \\
& Aumento en la frecuencia cardiaca, disminuye la frecuencia \\
Ira & cardiaca, aumento en la presión arterial diastólica, aumento en la \\
& actividad electrodérmica, aumento en la actividad electromiografía \\
& frontal y en los extensores de los dedos. Aumenta la temperatura \\
& cutánea digital y cefálica. Aumenta el volumen del pulso digital. \\
& Aumenta la frecuencia respiratoria sin cambios en la profundidad de la \\
& respiración. \\
& Aumento en la frecuencia cardiaca, aumento en la presión arterial \\
& sistólica. \\
Dolor & Disminuye la temperatura digital, aumenta la actividad electrodérmica, \\
& disminuye la actividad electrodérmica, frecuencia respiratoria estable, \\
Tristeza & con aumento de la profundidad de la respiración. \\
& Disminuye la frecuencia cardiaca, cambios respiratorios similares a los \\
& de la tristeza. \\
&
\end{tabular}

Lykken, 1957 en Verschuere, Crombez, Koster \& Uzieblo (2006), realizó un experimento con prisioneros colocándolos en un grupo de psicópatas y no psicópatas según un juicio clínico. Todos los prisioneros participaron en un condicionamiento aversivo, en el cual una campana sonaba justo después de que recibían un choque eléctrico. Los resultados muestran que los prisioneros psicópatas muestran una menor actividad anticipatoria de conductancia de la piel en comparación a los prisioneros no psicópatas.

Otras investigaciones enfocadas en las correlaciones psicofisiológicas de la conducta antisocial, una meta análisis de 95 estudios revelan que los desórdenes 
antisociales se relacionan con una reducción en la actividad de la conductancia de la piel ya sea en descanso, durante alguna tarea y en respuesta a una variedad de estímulos. (Verschuere et. al., 2006)

En personas adultas se ha encontrado una reducción en la conductancia de la piel. Pastor, (2003) examino la activación fisiológica hacia imágenes emocionales o neutras en prisioneros agrupados en psicopatía, psicopatía mixta y sin psicopatía según criterios del PCL-R. Tanto los psicópatas como los psicópatas mixtos mostraron una conductancia de la piel reducida hacia todas las imágenes.

La investigación psicofisiológica en psicópatas sugiere que las dos facetas de la psicopatía se caracterizan por correlatos psicofisiológicos distintivos. El primer factor, desapego emocional, está asociado a una reducción de la respuesta a estímulos aversivos, y se ha interpretado como un déficit en la respuesta al miedo. El segundo factor, el comportamiento antisocial se relaciona a una baja activación autonómica y se observa principalmente en una actividad reducida en la conductancia de la piel. (Verschuere et. al., 2006)

\subsection{Polígrafo}

A menudo el polígrafo se etiqueta como "detector de mentiras", pero no detecta mentiras sino ciertos cambios periféricos que pueden traslucir ansiedad, miedo, culpa o una respuesta de orientación por parte del examinado. El que estos estados internos se asocien o no con el engaño es otra cuestión. Mentir puede o no dar lugar a ansiedad, miedo, etc., y estas emociones pueden deberse al acto de mentir o bien a otros factores. (Garrido, E., Masip, J. \& Herrero, M. C., 2006)

El polígrafo es una técnica, basada en las respuestas psicofisiológicas del cuerpo relacionadas con las reacciones fisiológicas del mismo al dar una información inventada cuando se le da la instrucción contraria. Comúnmente el polígrafo se utiliza cuando en las investigaciones policiales existen datos que son difíciles de clarificar, pues en ocasiones las declaraciones tanto de los testigos como de los victimarios, 
pueden omitir cierta información, pues creen que no son importantes (Iacond \& Patrick, 2006).

Es importante mencionar el uso del polígrafo como principal antecedente de los analizadores de estrés de voz y por lo tanto abarcar de manera general un poco de la historia de este. Los inicios del polígrafo fueron a principios del siglo XIX con el criminólogo italiano Lombroso, que utiliza el pletismógrafo para medir la velocidad del pulso y el volumen sanguíneo durante los interrogatorios criminales, ya que los cambios en estas áreas se relacionan con cierta deshonestidad en las personas. (Clifton, 1991 en Hernández Fernandez y Alonso Quecuty, S.F). Después del trabajo de Lombrosso el polígrafo tiene dos grandes protagonistas; principalmente en la Universidad de Harvard de los Estado Unidos de América donde tuvo su nacimiento a principios del siglo XX. En 1908 Hugo Munstenberg, profesor de esta universidad e innovador del campo de la psicofisiología y la criminología propuso teóricamente el uso de tres monitores de análisis en la detección del estrés emocional parecidos a los utilizados en los polígrafos actuales. Otro precursor fue William Moulton Martson, el desarrolló el primer detector de mentiras específicamente por utilizar el monitoreo de la presión sanguínea para evaluar la deshonestidad entre sospechosos de ilícitos. (Benavides, 2007). En 1971 el afirmaba que existe una alta correlación entre las mentiras y los cambios en la presión sanguínea, de igual forma es el primero en hablar del "detector de mentiras". (Clifton, 1991 en Hernández Fernandez y Alonso Quecuty, S.F).

Normalmente los registros poligráficos comprenden la respuesta psicogalvánica, la presión sanguínea relativa, el ritmo cardiaco y la respiración. Para ello es necesario colocar unos electrodos sobre los dedos del sujeto mediante los cuales se tomas las medidas sanguíneas, y unos tubos flexibles alrededor del pecho y del abdomen para las medidas respiratorias. (Garrido, E., Masip, J. \& Herrero, M. C., 2006)

Garrido et. al. (2006) menciona que la cuestión fundamental en un examen poligráfico consiste en la comparación entre la reactividad fisiológica ante diversos tipos de preguntas. Existen varios procedimientos poligráficos, entre los cuales 
destacan la Prueba de Pregunta Control (Control Question Test o CQT), reetiquetada como Prueba de la Pregunta de Comparación (Comparison Question Test, también CQT, y la Prueba del Conocimiento del Culpable (Guilty Knowledge Test o GKT).

Ahondando un poco más en los tipos de preguntas usadas en las pruebas poligráficas, las cuales han servido de modelo a las que se emplean en otros tipos de técnicas, las más importantes son las siguientes: Relevantes, se relacionan directamente con el suceso investigado, se espera que provoquen las emociones y los cambios fisiológicos correspondientes para poder distinguir entre culpables e inocentes, se formulan de manera que convenza al interrogado de que se piensa que se es culpable; irrelevantes o neutras, no guardan ningún tipo de relación con el suceso que se investiga; control, poseen un contenido altamente significativo, pero sin importancia para el hecho que se investiga, se plantean sobre cuestiones que afectan emocionalmente a todas las personas y el objetivo al formularlas es acosar al sospechoso. (Martínez, 2005)

En el año del 2003, la National Research Council (NRC), de los E.U. publicó un informe detallado sobre el polígrafo, este informe consta de casi cuatrocientas páginas en la que se examina una larga serie de aspectos científicos y prácticos relacionados con el empleo del polígrafo. (Garrido Et. al., 2006). Entre los principales puntos encontrados en este informe están: los estados psicológicos asociados con el engaño pueden reflejarse en las respuestas fisiológicas que mide el polígrafo; sin embargo, tales estados pueden darse también en ausencia de engaño. Además otros factores psicológicos y fisiológicos (por ejemplo la ansiedad la ser sometido a la prueba) también influyen sobre las respuestas medidas por el polígrafo. Por lo tanto la NRC concluyó que "hay una falta de correspondencia considerable entre los datos fisiológicos que el polígrafo proporciona y los constructos subyacentes que los examinadores poligráficos creen que miden". Aunque mentir siempre produjera los cambios fisiológicos que se miden, la presencia de tales cambios no significaría necesariamente que se estuviera mintiendo, ya que pueden ser causados por otros factores distintos. 
Las conclusiones finales de NRC referentes a la validez del polígrafo son que este puede discriminar entre personas veraces y mentirosas que no hayan sido entrenadas en estrategias para burlar al polígrafo, alcanzando una precisión significativamente superior al azar, pero por debajo de la perfección.

La prueba poligráfica, puede agruparse en dos grupos de técnicas: "las que tienen por objetivo descubrir la verdad o la mentira del evaluado (técnicas de engaño), y las que buscan corroborar si el sujeto tiene o no información relacionada con algún crimen (Técnicas de información)” (Vila, 19996 en Godoy-Cervera \& Dzib-Aguilar, 2010)

A continuación se mencionan las principales técnicas para la detección del engaño usadas en las pruebas poligráficas.

\subsection{Técnicas de Engaño}

Esta técnica pretende conocer la credibilidad de un sujeto interrogado (Raskin, 1994). Son de mayor uso en procesos penales, aunque también se usa en proceso de selección de personas para evaluar su confiabilidad u honestidad. Esta modalidad de técnicas poligráficas esta agrupada en tres formatos de aplicación y calificación; buscando los dos últimos formatos, mejorar la validez diagnóstica de sus resultados. Siendo estas técnicas: Relevancia-Irrelevancia, Pregunta Control y Control de Mentira Directa.

Las técnicas de engaño poseen características generales. Entre las cuales se refiere a las preguntas que se le formularan a los sujetos evaluados; estas deben ser: directas, claras, precisas. Lo cual supone que con los cuestionamientos no se debe buscar del sujeto su estado mental ni la interpretación que el evaluado pueda tener de los contenidos de lo cuestionado. El evaluado debe conocer todas las preguntas que se le formularan durante el interrogatorio y la medición psicofisiológica, pero no el orden de la presentación. Por lo general se le aplican entre 10 y 12 preguntas en tres series. En el cuestionario que se elabora a partir de la conducta antisocial por evaluar; 
se formulan varios tipos de preguntas según el formato que se elija utilizar. Siendo los tipos de preguntas (Raskin, 1994):

a) Sintomática (I), es la pregunta que busca circunscribir el contenido por evaluar, para que elementos externos que se encuentran en la motivación del sujeto disminuya su incidencia en las respuestas psicofisiológicas que emita el evaluado. Ejemplo: ¿Te quedo claro que solo te preguntaré los cuestionamientos que ya hemos revisado?

b) Relevante de Sacrificio (S.R.), se diseñó para introducir al sujeto al tema por evaluar. Ejemplo: Con respecto a la violación de la menor ¿contestaras honestamente a cada pregunta?

c) Irrelevante o Neutra $(\mathrm{I} / \mathrm{N})$ su función es de línea base. Ya que se caracterizan por preguntas donde el sujeto no pueda mentir ya que no le crea ningún compromiso hacia el evento evaluado y por lo tanto no le produce impacto emocional. Ejemplo: ¿Hoy es viernes?

d) Control (C), buscan crear en el evaluado una situación emocional mayor, en comparación con las respuestas psicofisiológicas que producen las preguntas relevantes. Estas preguntas deberán abarcar largos periodos de tiempo de la vida del sujeto; ser similares en naturaleza pero sin relacionarse de marea especifica al problema evaluado. Ejemplo: Durante los últimos 15 años de tu vida, ¿has ocultado una parte de tus conductas sexuales?

e) Control de Mentira Directa (M. D.), propositivamente se le induce al sujeto a mentir, para conocer sus reacciones fisiológicas. Ya que son preguntas que difícilmente, casi imposible no las haya cometido el evaluado a lo largo de su vida. Esta pregunta se caracteriza por pedirle al encuestado que conteste con un "no" a los cuestionamientos; lo anterior busca estandarizar las preguntas control; con ello disminuir algunas imprecisiones que genera la pregunta control típica. Ejemplo: Durante su vida ¿ha dicho alguna mentira?

f) Relevante (R) pretende crear en el sujeto respuestas psicofisiológicas diferentes, en comparación con las respuestas irrelevantes, control típica o la respuesta control de Mentira Directa. Dicha diferencia se relaciona a un 
impacto emocional en el sujeto, lo cual bajo ciertos criterios de calificaciones psicofisiológicos, se interpreta como respuestas veraces o falsas. Ejemplo: ¿Usted tuvo relaciones sexuales con la menor en la casa de la misma?

En cuanto a las indicaciones y las características de la aplicación durante el interrogatorio psicofisiológico se deben considerar:

a) Las respuestas deben ser con monosílabos, sí o no.

b) El sujeto no se debe mover ni hablar durante el interrogatorio.

c) Se le recuerda que debe contestar cada pregunta con sinceridad.

d) Si al sujeto le ocurre cualquier cosa durante el interrogatorio lo debe reportar inmediatamente después del mismo y no durante.

e) Entre cada pregunta debe haber un espacio de tiempo de 25 a 35 segundos.

f) El sujeto contestara la pregunta que se le plantea, esperando un periodo aproximado de 5 segundos.

g) Las preguntas se harán en 3 series sucesivas.

h) En cada serie las preguntas neutras y de control se rotaran en sus tres posiciones, evitando que el sujeto tenga respuestas anticipatorios.

i) Si los resultados no son concluyentes se pueden hacer dos repeticiones más.

j) El aplicador debe conducirse con una actitud de seguridad.

En cuanto a las maneras de interpretar y calificar los resultados psicofisiológicos impresos en las cartas poligráficas (Raskin, 1994):

a) Las respuestas psicofisiológicas se interpretan comparando la fuerza relativa de la pregunta relevante versus la irrelevante, control o mentira directa; según sea la técnica utilizada.

b) Criterios fisiológicos que se observan en la carta poligráfica; siendo estos: supresión, bloque, aceleración, lentificación, incremento de amplitud, decremento de amplitud, cambio de línea base, complejidad, duración, incremento de ritmo, decremento de ritmo, contracción ventricular prematura, cambio en la posición del cote diacrótico y amplitud.

c) La calificación de las respuestas psicofisiológicas se pueden realizar de tres maneras: global, numérica e informatizada. La global se caracteriza por ser 
una apreciación cualitativa de la presencia o ausencia de los criterios psicofisiológicos; así como la integración de la información recogida del caso; siendo la menos precisa. La numérica es un método sistematizado que se centra en los resultados psicofisiológicos, asignándole valores numéricos por su dirección y su magnitud; calificando con valor positivo si la respuesta control es mayor que la relevante, valor negativo si la respuesta control es menor que la relevante y cero si no existen diferencias. Por último la calificación informatizada que es un procedimiento de calificación objetivo y el más fiable; sustentando en el teorema de Bayes que calcula en probabilidades estadísticas la sinceridad de las respuestas fisiológicas de los sujetos evaluados.

Las técnicas de engaño han ido mejorando su validez y confiabilidad. A continuación se presentan dichas técnicas, de la menos confiable y valida a la más confiable y valida.

\subsubsection{Técnica de preguntas Relevantes e Irrelevantes: Es el conocimiento de} la fuerza relativa de las reacciones fisiológicas autónomas entre la pregunta relevante y la pregunta irrelevante. Por ejemplo: pregunta relevante ¿usted robo la computadora de su trabajo? y la pregunta irrelevante ¿Vive en Mérida? Actualmente es de escaso uso por sus imprecisiones al aplicarse e interpretarse.

Esta técnica se aplica en una serie de 10 a 15 preguntas formada por preguntas relevantes e irrelevantes o neutras, mientras se mide las respuestas psicofisiológicas de manera continua. La interpretación de los resultados son simplistas y psicofisiológicamente básicos ya que lo que se busca, es si existen reacciones diferentes o iguales psicofisiológicas entre las preguntas relevantes y las irrelevantes. Llegando a la conclusión de que si las reacciones psicofisiológicas son mayores en las preguntas relevantes el sujeto mintió y si no existen diferencias el sujeto se condujo con sinceridad. Esta forma de calificar introduce ruido en sus interpretaciones ya que estados emocionales provocados por las preguntas y no por el contenido a evaluar hacen que las interpretaciones sean erróneas. En un estudio donde se evaluaron las 
gráficas psicofisiológicas cuantitativamente con preguntas Relevantes-Irrelevantes, se encontró que obtuvieron de falsos positivos cero pero de falsos negativos del $73 \%$. Al igual las personas hiperreactivos e hiporreactivos no pueden ser diagnosticadas confiable mente (Horowitz, 1988 en Raskin, 1994).

\subsubsection{Técnica de Pregunta Control: Busca crear "estándares emocionales"} (Summers, 1939) en el sujeto evaluado de sus respuestas psicofisiológicas, en experiencias emocionales diferentes que le provocan mayor o igual emotividad en comparación con el contenido de la evaluación poligráfica; siendo la "pregunta de respuesta comparativa" (Reid, 1947).

La pregunta control se caracteriza por cuestionamientos generales, abarcando largos periodos en el tiempo pero similar al contenido evaluado. Crea en el sujeto un dilema, con respecto a la impresión que puede darle al entrevistador sobre su honestidad. El número de preguntas pueden ser 3 o 4 y van en relación al número de preguntas Relevantes. Los criterios de interpretación se basan en que si el sujeto presenta más reacciones psicofisiológicas en las preguntas control, son por que el evaluado se preocupó en su fracaso por el engaño en las preguntas control, o por la falta de confianza de que sus respuestas fueron totalmente sinceras, lo cual se interpreta como respuestas veraces. Pero si a pesar de los anteriores supuestos el sujeto presenta reacciones psicofisiológicas más altas en las respuestas relevantes, se interpreta como indicadores de engaño. Cuando las diferencias no son claras en ambas direcciones los resultados se interpretan como no concluyentes.

La Ventaja de la pregunta control es que busca establecer un referente de comparación del estado emocional alterado, por experiencias connotadas por el sujeto como importantes. Lo anterior permite hacer una comparación psicofisiológica de mayor equidad con la pregunta Relevante y no así como se hace con la pregunta neutra o Irrelevante. Las desventajas que presenta son la equidad mencionada arriba es supuesta y no empírica; se requiere la capacidad creativa y artesanal del entrevistador para diseñar las preguntas Control; dificultades en su administración; 
apreciación de los evaluados como ofensivas y difíciles de explicar a los profesionales de la aplicación de justicia.

En cuanto la validez de manera general se encontró que en estudios de laboratorio, los falsos positivos fue el 3\% de error y en los falsos negativos el $7 \%$. Los estudios de campo reportan que los falsos positivos fueron el $20 \%$ de error y en los falsos negativos el 10\% (Raskin, 1994)

1.9.3. Técnica de pregunta de Mentira Directa: Es la pregunta que cuestiona un comportamiento que difícilmente, casi imposible un sujeto no haya realizado. Por tal característica se le pide al evaluado que conteste con una mentira; permitiendo tener una línea base de sus respuestas fisiológicas ante una mentira "segura".

La pregunta de Mentira Directa se aplica y se interpreta de igual manera que la pregunta Control, con la particularidad que se le pide al sujeto que mienta en su respuesta cuando se le formule la Pregunta de Mentira Directa; Sustituye a la pregunta Control.

Tiene por ventajas todos los inconvenientes de la Pregunta Control, excepto la equidad fisiológica con la pregunta Relevante, ya que sigue siendo supuesta y no empírica.

Los resultados de campo y laboratorio son consistentes en cuanto su valides, reduciendo los falsos positivos (Raskin, 1994).

1.9.4. Técnicas de Información o Pico de Tensión: Su función es medir la fuerza relativa de las reacciones psicofisiológicas a unidades de información específica, para determinar si el sujeto tiene conocimiento o no de dicha información (Lykken, 1981; Raskin, 1982). A diferencias de las técnicas de engaño no evalúan de manera directa la credibilidad de las respuestas del sujeto. Son 2 las técnicas de uso en esta modalidad, la de Tensión Máxima y las de conocimiento ocultado. Cada técnica tiene sus características particulares en la aplicación, calificación e interpretación de resultados; así como en su validez. 
1.9.5. Técnica de Tensión Máxima o Solución Conocida: Se diseñó para determinar si el sospechoso conoce la alternativa correcta entre un conjunto de cinco o más opciones que se relacionan a un suceso, que sólo los investigadores o personas involucradas conocen del caso. Se aplica con las siguientes características básicas:

a) El primer cuestionamiento no debe contener el ítem crítico o correcto

b) El primer cuestionamiento no se contabiliza en la evaluación general

c) El ítem correcto se sitúa cerca de la mitad de la secuencia

d) Los investigadores conocen la respuesta correcta

e) Cuando los investigadores lo utilizan para conocer alguna información que ignora se le llama "Técnica de Tensión Máxima"

f) Los cuestionamientos se realizan con un rango de tiempo de 15 segundos

1.9.6. Técnica de Conocimiento Oculto o Búsqueda: Es para determinar si el sospechoso está intentando ocultar información (Lykken, 1959). Se aplica con las siguientes características básicas:

a) Se usan 5 preguntas de elección múltiple, con seis opciones cada una

b) Cada pregunta cuestionan información independiente

c) Las opciones correctas se rotan entre la posición segunda o sexta

d) La opción sirve de choque y no se evalúa

e) Se discute con él evaluado el contenido de una preguntas pero no las opciones y se le aplica; así sucesivamente hasta cubrir todas las preguntas

f) Se formula la pregunta y se presentan las opciones en periodos de tiempo de 15 segundos entre cada una

g) El evaluador debe alentar al sujeto que revele cualquier información

h) El evaluador debe cuidar de no dar información al sujeto

Los procedimientos para calificar e interpretar los resultados de la técnica de Conocimiento Ocultado o Búsqueda se basan en las siguientes características:

a) Sí las reacciones psicofisiológicas son consistentemente elevadas en las opciones correctas, indica que el sujeto oculta información de la temática evaluada. 
b) La respuesta electrodermal es el indicador más confiable para discriminar la veracidad del sujeto (Podlesny y Raskin, 1978).

c) La respuesta electrodermal y la respiración permitieron discriminar entre personas culpables e inocentes (Iacono, Cerri, Patrick y Fleming. 1987).

d) Sistema de puntuación credo por Likkem (1959), que consiste en asignarle puntuaciones numéricas del cero (0), 1 y 2 a las reacciones psicofisiológicas de las opciones que fungen como distractores de la pregunta planteada; comparándolas con la opción cierta. Se le asigna la puntuación de 2 a la reacción mayor, 1 a la segunda reacción mayor y cero (0) si fue la tercera mayor o inferior. Se suman los totales de cada pregunta y se divide entre el total de la puntuación máxima posible. Si el resultado obtenido de la división sobrepasa a .50 se concluye que el sujeto oculto conocimiento. Si es menos de .05 se concluye lo contrario.

\subsection{Potenciales Evocados}

En Garrido Et. al. (2000) se define a los potenciales evocados como picos que aparecen en el electroencefalograma (EEG), como respuestas a una acontecimiento

discreto como la presentación de un estímulo. Uno de estos picos es llamado P300 o P3, este aparece ante estímulos llamativos o significativos para el sujeto.

Rosenfeld (2002) indica tres aspectos del P300 que son relevantes en tareas de conocimiento oculto. Primero la amplitud, es decir, la altura de la onda. el segundo es el perfil, es decir, la distribución de amplitudes en las zonas parietal, central y frontal. El tercer aspecto relevante es la latencia, es decir, el tiempo que tarda la onda en aparecer desde la presentación del estímulo. El P300 ha demostrado ser útil para discriminar entre verdades y mentiras en tres paradigmas experimentales distintos: a) simulación de pérdida de memoria; b) conocimiento oculto de objetos robados y de realización de actos ilegales; y c) detección de memorias falsas. 


\subsection{Analizadores de Estrés de Voz}

Los Analizadores de Estrés de Voz tienen una larga historia de desarrollo, la cual comenzó en 1970 con diferentes individuos y compañías compitiendo por alcanzar la última tecnología para ser introducida al mercado (Damphouse, Pointon, Upchurch, Moore, 2007).

El análisis de estrés de voz se origina del concepto de que cuando una persona está bajo estrés, especialmente cuando el entrevistado está bajo "jeopardy”, el cuerpo se prepara para pelear incrementando la reacción de los músculos para brincar a la acción (Xiangfeng, 2005).

En el año de 1971, Olof Lippold, investigador de la Universidad College London, quien publicó en la gaceta "Scientific American" los resultados de su investigación, llamada Tremores Fisiológicos, la cual se basaba en los trabajos iniciados una década antes por los doctores Martin Holliday y Joseph Redfearn en el hospital Nacional de Londres. (Benavides, 2007). Holliday y Redfearn habían descubierto en la zona de la laringe la contracción de un musculo voluntario que era acompañado por tremores de diminutas oscilaciones. Años después descubrieron que la mayoría de este tremor fisiológico consistía en la oscilación de un mecanismo reflejo involuntario con frecuencias entre 8 y 12 Hertz que controlaba la tensión de los músculos estriados alrededor de las cuerdas vocales. (Benavides, 2007).

Lippold midió los efectos de la contracción de músculos voluntarios en microtemblores (oscilaciones pequeñas). En el campo de la detección del engaño, su trabajo se ha interpretado en que el esfuerzo voluntario para engañar resultara en micro-temblores medibles. Estos micro-temblores afectan las cuerdas vocales de tal manera que un examen meticuloso de los patrones de voz puede revelar el engaño. De hecho, muchos desarrolladores de "detectores de mentira" por estrés de la voz no aseguran poder detectar mentiras. En cambio, ellos dicen que sus dispositivos son capaces de detectar los micro-temblores (o alguna variante), lo que podría estar relacionado con el estrés de tratar de ocultar algo o engañar. Así, varios dispositivos 
son creados y refinados para medir cambios en los patrones de respuesta vocales cuando un sujeto trata de engañar. Estos softwares o programas son nombrados genéricamente como Análisis de Estrés de Voz (VSA por sus siglas en ingles. (Damphouse, Pointon, Upchurch, Moore, 2007)

Al mismo tiempo el Departamento de Contrainteligencia del Ejército de Estados Unidos de América en Fort Holabird, Maryland; había utilizado aparatos rudimentarios en la guerra de Vietnam, usados por el ejército norteamericano para identificar guerrilleros del Vietcong infiltrados entre civiles. (Benavides, 2007; Palmatier, s/f)

Para Hopkins, S.; Benincasa, D.; Rattley, R.; Grieco, J. (2005), el Análisis del Estrés de la Voz se origina del hecho de que cuando una persona está bajo estrés, los temblores del micro-músculo ocurren en los músculos que conforman el tracto vocal los cuales son transmitidos al habla.

En 1971, Dektor Counterintelligence and Security Inc., (Savannah, Georgia) desarrolló un instrumento para detectar estrés, el cual fue llamado "Psychological Stress Evaluator" (PSE). El Manual del curso de Examinadores certificados del "National Institute for Truth Verification" (NITV) declara que el PSE detecta microtemblores sub-audibles en la voz humana, y que el análisis de estos temblores relacionados con el estrés tiene una gran utilidad para la detección del engaño. (Cestaro \& Janniro, 1996)

Avances tecnológicos recientes, sugieren que puede existir cierto futuro en la investigación de la efectividad de aparatos que midan los cambios fisiológicos en los patrones de modulación de voz relacionados al estrés. Los fabricantes de los aparatos para el Análisis de Estrés de Voz (VSA por sus siglas en inglés) sugieren que las personas que traten de engañar a un entrevistador experimentaran una cantidad medible de estrés (el mismo tipo de estrés que es medido por una máquina de poligrafía). Así como el estrés afecta el ritmo cardiaco, el ritmo de la respiración y la respuesta galvánica de la piel, el efecto del estrés relacionado al engaño en las cuerdas vocales supuestamente puede ser medido de tal forma que el engaño puede ser observado. Se dice que los aparatos de VSA son capaces de medir el efecto 
fisiológico del engaño con una mayor precisión, menor entrenamiento, menor invasión, menor costo y mayor inmediatez de los hallazgos a comparación con el uso de un examen poligráfico. (Damphouse, Pointon, Upchurch, Moore, 2007)

El uso del VSA en Estados Unidos se ha extendido a través de un gran número de agencias policiacas en diferentes estados de la nación (Damphouse, Pointon, Upchurch, Moore, 2007), siendo California; Ohio, Florida y Missouri los estados con mayor número de agencias con 162, 161, 144 y 138 respectivamente. En México el VSA se introduce por medio del coronel retirado del departamento de inteligencia militar de EE UU, Michael W. Savage, quien en marzo de 1999 por conducto del Instituto Panamericano de Ciencia y Tecnología introdujo por primera vez la tecnología del VSA en Latinoamérica en la ciudad de Monterrey N.L. México. (Baker Group International, 2008).

El proceso del VSA para detectar el engaño es similar al usado en las pruebas poligráficas. Los examinadores del VSA usan entrevistas pre-test para preparar al sujeto para la prueba real. El propósito de este proceso es establecer la credibilidad de los procedimientos de la prueba, desarrollar el rapport con el sujeto, hacer observaciones de la conducta del entrevistado, crear preguntas para la prueba y romper cualquier barrera internalizada por el sujeto al hacer admisiones. (Hopkins, S.; Benincasa, D.; Rattley, R.; Grieco, J., 2005)

El software de los programas de VSA está diseñado para medir los cambios en los patrones de voz causados por el estrés, o el esfuerzo físico, o por tratar de ocultar respuestas engañosas. Los programas de VSA interpretan los cambios en los patrones de voz e indican por medio de una gráfica si el sujeto está siendo "deshonesto" u "honesto". (Damphouse, s/f)

El software usado en los diferentes programas del VSA se basa en evaluaciones de los cambios en el patrón de la voz los cuales son causados por el estrés asociado al dar respuestas engañosas. La voz humana tiene dos componentes fundamentales, la amplitud modulada (AM) y la frecuencia modulada (FM). El sonido AM es audible mientras que el FM no puede ser escuchado por el oído humano. El aumento del 
estrés da como resultado una perdida en la frecuencia modulada. (Damphouse, Pointon, Upchurch, Moore, 2007)

Hay dos maneras básicas en cómo funcionan los sistemas de VSA (Hopkins, Ratley, Benincasa \& Grieco (2005). El primero, el VSA basado en la energía, funciona bajo los presupuestos del trabajo de Lippold detectando los temblores del micro-músculo que se dan durante una respuesta engañosa a una pregunta. Si una persona intenta engañar, entonces experimentará estrés. Este estrés dará como resultado un patrón de forma de onda medible que indicara el "engaño". Si la persona no está intentando engañar, entonces no experimentará estrés, y su respuesta arrojará una forma de onda medible que indica "no engaño".

El segundo tipo de VSA, basado en frecuencia, se apoya en el mismo principio básico que los VSA basados en energía, pero se enfoca en cómo se distribuyen las frecuencias dentro de una banda de frecuencias. Un ejemplo de este tipo de VSA es el LVA (Layered Voice Analysis) el cual fue desarrollado en Israel por Amir Lieberman, el aplicó algoritmos matemáticos a las frecuencias de la voz. El fabricante de este producto reporta que las agencias de seguridad, inteligencia y del cumplimiento de la ley han estado usando esta tecnología desde el año 2000. (Damphouse, et. Al., 2007)

El software del LVA asegura estar basado en 8000 algoritmos matematicos aplicados a 129 frecuencias de la voz. Aunque se reporta estar basado en la frecuencia de la voz, la metodología exacta aplicada en eso aun deber ser expuesta para una revisión científica. La diferencia clave entre la tecnología del LVA y del CVSA es que el primero afirma poder identificar la causa del estrés mientras que el CVSA solo la existencia del estrés. (Damphouse, et. Al., 2007)

Existen dos factores importantes a tomarse en consideración en el uso de un programa de VSA, el primero es la sensibilidad, definida como la probabilidad condicional de que un sistema identifique el engaño cuando el engaño este presente (Hopkins, S.; Benincasa, D.; Rattley, R.; Grieco, J., 2005), esto se refiere a la habilidad del software para identificar correctamente el engaño. La sensibilidad se expresa como un porcentaje, en el cual se compara el número de engañadores 
identificados correctamente divididos por el número de engañadores dentro de toda la muestra, multiplicado por 100 (Damphouse, Pointon, Upchurch, Moore, 2007). El segundo factor importante es la especificidad, definida como la probabilidad condicional de que un sistema identifique honestidad cuando la honestidad este presente, (Hopkins, S.; Benincasa, D.; Rattley, R.; Grieco, J., 2005), esto se refiere a el porcentaje de entrevistados no-engañadores correctamente identificados como noengañadores. Un equipo con una especificidad perfecta detectara correctamente el 100\% de todos los no-engaños. (Damphouse, Pointon, Upchurch, Moore, 2007).

Desde su aparición en la década de 1970 los dispositivos de VSA han sido objeto de muchas investigaciones que han buscado esclarecer si estos equipos son eficaces para detectar en el engaño. En los siguientes párrafos se mencionan los resultados de algunas de estas investigaciones.

En un reciente estudio realizado por el Naitional Institute o Justices (NIJ), dos de los programas de VSA más populares usados por los departamentos de policía alrededor de Estados Unidos, no son mejores que arrojar una moneda para detectar el engaño acerca del uso reciente de drogas. Entre los hallazgos de este estudio también se señala que la mera presencia de un programa de VSA durante un interrogatorio puede disuadir al entrevistado de dar una respuesta falsa. (Damphouse, s/f)

Se han realizado diversas investigaciones para analizar la validez y confiabilidad de estos instrumentos en el quehacer judicial, estas investigaciones han arrojado diferentes resultados, investigadores del "Air Force Research Laboratory" (Hansen and Zhou, 1999; Haddad, Ratley, Walter, and Smith, 2002) mostraron que dos programas de VSA (Lantern and the Psychological Stress Evaluator) fueron capaces de reconocer el estrés en patrones de la voz. Concluyeron que varios indicadores en los patrones de habla de un individuo son diferentes cuando esta estresado y que estas diferencias pueden ser medidas. Sin embargo, reportaron que no existió suficiente evidencia para afirmar que los analizadores de estrés de voz, detectan el engaño. En otro estudio, Meyerhoff, Saviolakis, Koenig and Yourick, dirigieron un estudio comparativo del CVSA, en oposición a indicadores médicos del estrés como los son la presión sanguínea, ACTH en el plasma, y niveles de cortisol en 
la saliva. No se encontró relación entre estos indicadores médicos y las predicciones del CVSA para el estrés. (Damphouse, Pointon, Upchurch, Moore, 2007)

Cestaro (1996) encontró que una el CVSA (Computer Voice Stress Analyzer) técnicamente como el fabricador lo describe, mide cambios en los patrones de la voz. Cuando el comparó las tasas de precisión de la detección del engaño del polígrafo y el CVSA en un escenario de crimen fingido encontró que para el CVSA sus resultados arrojaban una precisión de solo el 52\%, lo cual es no es más significativo que el azar.

Sin embargo Wylie (2001) afirma que el uso de instrumentos de VSA puede dar como resultado a respuestas menos deshonestas en ciertas condiciones.

Otro resultado favorable para el VSA fue hecho por Hopkins et al. (2005), ellos examinaron grabaciones de 56 entrevistas de casos criminales. Ellos encontraron que la precisión promedio de cinco diferentes programas de VSA que evaluaron las entrevistas para encontrar engaño fue aproximadamente del 68\%. También encontraron que la precisión aumenta un poco cuando las personas que usaron el equipo tenían más experiencia trabajando con los mismos.

Como se ha mencionado en los párrafos anteriores se han realizado diversas investigaciones referentes a la eficacia, validez, confiabilidad de los equipos del VSA, pero en la presente investigación se usará un software del cual no se encontraron investigaciones que exploren las características mencionadas anteriormente. Este software es el Digital Voice Stress Analyzer (DVSA). En los siguientes párrafos se abordaran los orígenes de este software con el fin de que se posea mayor información y se tenga más familiaridad con éste.

Este software fue creado por el Dr. Gary Baker, ex trabajador de la empresa Diógenes Inc. el cual desarrollo los programas de entrenamiento y operación de los primeros VSA en el mercado. En el año 2001, estableció su propia compañía Baker Group International Inc. En cabo cañaveral Florida. (Baker Group International Inc. 2008)

El diseño su propio sistema, al que llamó Forensic Voice Anaysis System, integrándolo a su equipo comercial Digital Voice Stress Analyzer ${ }^{\circledR}$. El sistema DVSA o sistema Baker como también es conocido, a diferencia de sus competidores, 
que detectan de dos a tres signos de estrés por voz, ofrece según su diseñador el registro de 16 monitores fisiológicos dando una mayor flexibilidad y alta veracidad para el estudio y la interpretación de las gráficas de comparación, asegurando en su publicidad que los estados nerviosos o de angustia de los examinados no interfieren en la detección del estrés emocional, incluyendo el uso de medicamentos y alcohol. (Baker Group International Inc. 2008)

En el año 2001, estableció su propia compañía Baker Group International Inc. En cabo cañaveral Florida

El proceso del VSA para detectar el engaño es similar al usado en las pruebas del polígrafo, los examinadores del VSA usan entrevistas pre-test para preparar al sujeto para la prueba siguiente. El propósito de este proceso es para establecer la credibilidad de los procedimientos de la prueba, desarrollar el rapport con el sujeto, hacer observaciones del comportamiento de la persona, generar las preguntas para la prueba y romper cualquier barrera que pueda existir en el sujeto para hacer admisiones. (Hopkins, et al., 2005)

Tabla 2: Fases de aplicación del VSA

\section{FASE DESCRIPCIÓN}

1.- Diseño de protocolo En esta fase se determinaran las preguntas que se incluirán en el examen de VSA, se deberán combinar de acuerdo al objetivo, preguntas irrelevantes, relevantes y de control, cada pregunta deberá estar diseñada para responder con un sí o no.

2.-Aplicación del En esta fase el evaluador le realizará las preguntas del protocolo diseñado al protocolo evaluado.

3.-Analizar los resultados Ya que se hayan realizado las preguntas, las cuales se graban por medio de un micrófono al software instalado en un equipo, se analizan las respuestas en el software, generando un reporte final de gráficas. 
4.-Interpretación

Se interpretan las gráficas generadas y se determina si existe honestidad indicada o deshonestidad, de acuerdo al porcentaje de estrés mostrado en las gráficas de las preguntas en conjunto con la evaluación del comportamiento no verbal del evaluado.

\subsection{Inventario Clínico Multiaxial de Millon-III}

La importancia de considerar el uso del Millon-III en la presente investigación es para explorar si existen características de personalidad que puedan afectar la certeza o eficacia del uso del DVSA en la evaluación de la credibilidad de testimonio, es decir si existen correlaciones entre alguna característica de personalidad y que tan eficiente es el uso del DVSA para detectar cuando una persona es honesta o no deshonesta.

La teoría sobre la que se basa el MCMI-III se basa principalmente en una teoría evolutiva, la cual considera que los trastornos de personalidad son constructos evolutivos que se derivan de las tareas fundamentales a las que todos los organismos se enfrentan, es decir, la lucha por existir o sobrevivir, el esfuerzo de adaptar al medio o de adaptar el medio a uno mismo y la estrategia del organismo para invertir de forma reproductiva en los parientes o descendientes frente a una inversión en su propia replicación personal. (Millon, 2000)

Entre las características principales del MCMI-III se encuentra su brevedad, tiene 175 items, lo que lo hace más corto que otros instrumentos similares. Los ítems potencialmente discutibles fueron descartados y el vocabulario ha sido ajustado a un nivel de lectura de alumnos de secundaria. Este instrumento se puede completar en 20 o 30 minutos, lo que lo hace fácil de aplicar y minimiza el cansancio de los pacientes. (Millon, 2000)

Otra característica importante es que la estructura del MCMI es análoga al DSM a diferentes niveles. Primero, las escalas del MCMI se agrupan en las categorías personalidad y psicopatología para reflejar la distinción que hace el DSM entre el Eje II y el Eje I. se distingue mediante escalas diferentes las características de 
personalidad más duraderas de los pacientes (Eje II) y de los trastorno clínicos agudos que presentan (Eje I). En segundo lugar, en referencia a las escalas, cada eje se compone de dimensiones que reflejan sus síndromes más destacables. Así, las escalas del Eje II incluyen aquellas dimensiones de personalidad que han formado parte del DSM desde su tercera revisión y las escalas del Eje I reflejan aquellos síndromes que son los más notables e importantes en el trabajo clínico. (Millon, 2000)

El perfil de puntaciones del MCMI-III es útil para seleccionar e identificar a los pacientes que puedan requerir una evaluación más intensiva o atención profesional, los niveles más elevados en los subconjuntos de escalas pueden apoyar los juicios acerca de deterioro, severidad o cronicidad de la patología. A partir del examen del patrón de configuración de las 24 escalas clínicas en su conjunto pueden derivarse interpretaciones más dinámicas y comprehensivas de las relaciones entre sintomatología, conducta de afrontamiento, estilo interpersonal y estructura de la personalidad. (Millon, 2000)

Otro punto importante del MCMI-III son las posibilidades de emplearlo para fines de investigación. La conformidad creciente con los criterios del DSM-IV y el uso de puntaciones de prevalencia pueden ser especialmente valiosos al seleccionar grupos para la investigación. De esta forma se pueden usar puntuaciones objetivas, cuantificadas y con base teórica, junto con patrones de perfiles clínicos, para generar y poner a prueba una gran variedad de hipótesis clínicas, experimentales y demográficas. (Millon, 2000)

El enfoque de Millon parte de una teoría más integral y por lo tanto evalúa el trastorno de personalidad con más detalles y profundidad. A su vez, el inventario no solo aporta datos para el diagnóstico, sino también estrategias terapéuticas. No solo sirve su aplicación cuando existe trastorno de personalidad, sino también cuando hay rasgos y aun así cuando existen solo características, si bien un paciente puede consultar por depresión, no es lo mismo tratar una depresión en una persona que tiene características obsesivas, que otra con características narcisistas. Si bien la estrategia terapéutica en esencia es la misma, ésta cambia en cuanto a las tareas a realizar y las cogniciones a modificar de dicho paciente. Asimismo permite un análisis más 
exhaustivo en los casos más difíciles, que son aquellos que tienen un trastorno de personalidad combinado y da datos de la gravedad del mismo, evaluándolos en leve, moderado y severo, Caputto (2008).

\subsection{Crímenes de alta relevancia}

En este apartado se describirán las razones por las cuales se eligieron los delitos de robo, homicidio y violación como parte de la muestra y no otros delitos. Con respecto al homicidio y la violación la razón principal es que estos delitos son de alto

impacto a la salud y bienestar de la sociedad, tal es así que en Marchiori (1989) se encuentra una clasificación, sobre las características comunes propias de los sujetos que están internados dentro de una institución penitenciaria, por los delitos de homicidio y violación.

El homicida, es un interno que por lo general no ofrece problema de conducta, se adapta al sistema penitenciario, respeta a los celadores y demás internos. Trabaja en forma continua, no es violento. Esto es debido a que durante gran parte de su vida ha presentado normas y hábitos adaptados a su medio, la conducta delictiva irrumpe en él de un modo brusco. Pareciera la solución para equilibrar una descompensación de su personalidad patológica. Este interno en la institución difícilmente comete otro tipo de delitos, pero puede ser violento con la esposa, familiar o amigos. Muchas veces se acentúa las ideas paranoides y entonces el individuo puede llegar a una agresión por un conflicto que se desencadena en la institución penitenciaria.

El delincuente sexual, la problemática de personalidad de este interno está centralizada en el área sexual, es decir, que en todos los demás niveles de la conducta puede presentar un modo de vida pseudo-adaptada: área laboral, educacional y familiar. Utiliza diversos medios para sus conductas sexuales, ya que es consciente de que no controla sus impulsos. Es raro que manifieste un comportamiento agresivo con autoridades, tratará de no ser visto por los otros internos si realiza una conducta anormal sexual. 
Asimismo según Garrido y Sobral (2008), menciona que privar de la vida a otro, es la conducta humana más dramática para el criminal y desde luego para la víctima y para su estudio se deben tomar en cuenta que es una relación humana muy compleja. El homicida que actúa dentro de una telaraña de motivaciones, además del daño o destrucción de la víctima busca decir algo además de conseguir algo. La agresión física tiene no solo un contenido social, sino también un profundo significado psicológico que ha sido muy estudiado por diversidad de autores.

Con respecto al delincuente sexual, se usará la clasificación del criminólogo Hazelwood (1983) la cual describe una tipología de violadores compuesta por los siguientes cinco tipos:

1. Violadores que buscan ganar confianza

2. Violadores que quieren afirmar su identidad mediante el poder

3. Violadores que buscan la venganza o la expresión de ira

4. Violadores sádicos

5. Violadores oportunistas

Para él la violencia sexual es un hecho común a todas las sociedades, su expresión ha variado en función de condicionantes socioculturales, históricos y legales. La violación, el incesto, la agresión, abuso o acoso sexual constituyen comportamientos sexuales inadecuados, de gran relevancia social, que no se hallan recogidos en el sistema clasificatorio del DSMIV-TR (APA, 2000) sino en el Código Penal, Castro (2009).

El delito de robo posee una gran relevancia social debido a que el número de internos en el centro de reinserción social de Tekax, según datos proporcionados por los funcionarios que laboran en él es mucho mayor a otro tipo de delitos. De acuerdo al censo interno del CE.RE.SO. de Tekax para el mes de noviembre del año 2011, el número de personas recluidas en condición de sentenciado o procesado por el delito de robo eran 57 , lo que representa el $24.57 \%$ de la población total del CE.RE.SO. En la siguiente tabla se muestran las frecuencias y porcentajes de los delitos cometidos en este CE.RE.SO. 
Tabla 3: Frecuencias y porcentajes de delitos

\begin{tabular}{|c|c|c|}
\hline Delito & Frecuencia & Porcentaje \\
\hline Homicidio & 27 & 11.64 \\
\hline Lesiones & 30 & 12.93 \\
\hline Violación & 33 & 14.22 \\
\hline Robo & 57 & 24.57 \\
\hline Incumplimiento de obligaciones familiares & 17 & 7.33 \\
\hline Daño en propiedad ajena & 11 & 4.74 \\
\hline Fraude & 1 & 0.43 \\
\hline Contra la salud & 12 & 5.17 \\
\hline Allanamiento de morada & 1 & 0.43 \\
\hline usurpación de funciones públicas o profesionales & 1 & 0.43 \\
\hline Allanamiento de morada & 1 & 0.43 \\
\hline Ataques peligrosos & 4 & 1.72 \\
\hline Corrupción de Menores & 4 & 1.72 \\
\hline Portación de armas e instrumentos prohibidos & 20 & 8.62 \\
\hline Abuso de confianza & 1 & 0.43 \\
\hline Tráfico de menores & 1 & 0.43 \\
\hline $\begin{array}{l}\text { Falsedad de declaración judiciales e informes dados a la } \\
\qquad \text { autoridad }\end{array}$ & 1 & 0.43 \\
\hline Lenocinio & 4 & 1.72 \\
\hline Trata de personas & 1 & 0.43 \\
\hline Abuso sexual & 5 & 2.16 \\
\hline TOTAL & 232 & 100 \\
\hline
\end{tabular}




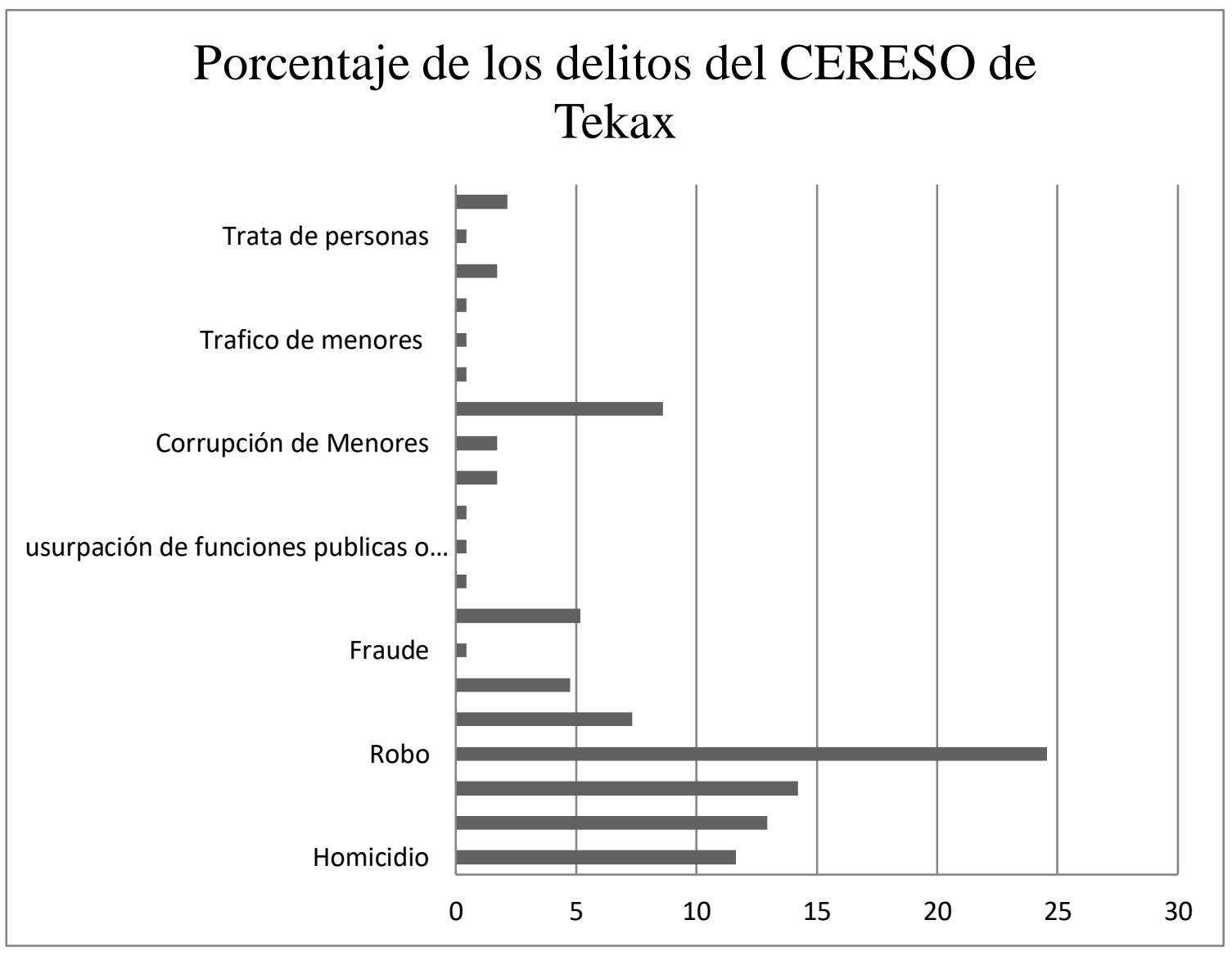

Figura 1: Grafico de Barras de Porcentajes de Delitos en el CE.RE.SO. de Tekax

Como se puede observar los delitos de robo, violación y homicidio son los de mayor frecuencia en el CE.RE.SO. de Tekax, solo seguidos de cerca por el delito de lesiones. Es importante considerar que estas frecuencias fueron tomadas en el mes de noviembre del 2011, estas cambian constantemente, por lo que se debe tener reservas si se quiere hacer generalizaciones acerca de las frecuencias de los delitos en el CE.RE.SO. de Tekax. 


\section{Capítulo 2. Método}

\subsection{Preguntas de Investigación}

a) ¿El uso del software DVSA es una herramienta eficaz (porcentaje de éxito para detectar correctamente a las personas que son honestas o deshonestas) para la detección del engaño en procesos de credibilidad de testimonio?

b) ¿Existirá relación entre los resultados de las evaluaciones de credibilidad y las características de personalidad de los participantes del estudio?

\subsection{Definición de variables}

Independientes:

Engaño.

Definición conceptual: el engaño se definen como el intento deliberado, exitoso o no, de ocultar, generar, y/o manipular de algún otro modo información sobre hechos

y/o emociones, por medios verbales y/o no verbales, con el fin de crear o mantener en otra(s) persona (s) una creencia que el propio comunicador considera falsa (Garrido et. Al., 2006)

Definición operacional: el hecho de que el participante mienta deliberadamente (negando haber realizado alguna acción) o no al entrevistador, cuando le fuere indicado en las instrucciones.

\section{Dependientes:}

Nivel de estrés en las respuestas de los sujetos.

Definición conceptual: Los cambios en los patrones de voz causados por el estrés, o el esfuerzo físico, o por tratar de ocultar respuestas engañosas (Damphouse, $\mathrm{S} / \mathrm{F})$. 
Definición operacional: El índice de estrés registrado en las gráficas obtenidas por medio del software DVSA ante las respuestas a las preguntas del cuestionario CQT.

Tipo de Delito

Definición conceptual: El delito del que se le acusa al participante y por el cual el participante está recluido en el CE.RE.SO.

Definición operacional: Cualquiera de los siguientes delitos: violación, homicidio o robo.

Características de personalidad

Definición conceptual: Elementos que conforman los patrones de pensamientos, sentimientos y conductas del individuo, las cuales son persistentes a través del tiempo y de las situaciones. (Morris \& Masito, 2005)

Definición operacional: Puntajes T mayor a 60 en las escalas del Millon-III.

\subsection{Participantes}

Se usó un muestreo no probabilístico por cuota para elegir a los participantes de la investigación. Se eligieron 24 internos varones entre 20 y 53 años de edad, con una media de 32.21 años. Ocho internos que hayan cometido el delito de violación, ocho internos que hayan cometido el delito de robo y ocho internos que hayan cometido el delito de homicidio, todos estos internos que se encuentran dentro del Centro de Reinserción Social (CE.RE.SO.) de Tekax, Yucatán. Del total de participantes 14 tienen una sentencia y nueve están en calidad de procesados.

Cuatro investigadores, estudiantes de la Facultad de Psicología de la Universidad Autónoma de Yucatán con capacitación básica en el uso del DVSA en procesos de credibilidad de testimonio. 


\subsection{Instrumentos y/o materiales}

a) Computadora tipo Laptop con el software Digital Voice Stress Analyzer (DVSA) para Windows XP, Versión 5.0, Bajo Licencia de Baker Group

b) Micrófono de pinza

c) Videocámara modelo Sony handycam,

d) Cuatro tipos de tarjetas diferentes con las instrucciones que los participantes realizaron. (ver Anexo)

Cuestionario de Tipo Control Question Test: Este cuestionario busca crear “estándares emocionales” (Summers, 1939) en el sujeto evaluado de sus respuestas psicofisiológicas, en experiencias emocionales diferentes que le provocan mayor o igual emotividad en comparación con el contenido de la evaluación poligráfica; siendo la "pregunta de respuesta comparativa" (Reid, 1947).

Inventario Clinico Multiaxial de Millon III: Este instrumento mide los estilos de personalidad y fue creado por Th. Millon, y C. Millon. \& Davis, R. (Millon, 2007). Tiene una consistencia interna realizada mediante Coeficiente Alfa de 0.660.89 y fiabilidad test-retest para las puntuaciones dimensionales de $0.85-0.93$; en cuanto a la validez se han realizado estudios de correlaciones entre las puntuaciones dimensionales del Millon-III han arrojado resultado moderados, por ejemplo con con el cuestionario de 90 sintomas revisado (SCL-90-R) y el inventario Multifasico de Personalidad de Minnesota (MMPI) la mayoría de estas correlaciones estan encima de 0.50 pero no llegan a valores más elevados. (Millon, 1997).

\subsection{Tipo de estudio y diseño}

El presente estudio es de tipo exploratorio, pues el tema a investigar es reciente y no existen investigaciones de esta temática en el estado de Yucatán. Se usó un diseño cuasiexperimental de ciego simple, en el que los participantes debían mentir al 
entrevistador y éste sin conocer las instrucciones seguidas por el entrevistado debía evaluar si estaba siendo honesto o deshonesto en sus respuestas, usando para ellos, el software Digital Voice Stress Analyzer (DVSA). Los participantes de esta tesis son internos del Centro de Reinserción Social de Tekax, Yucatán; los cuales han sido recluidos por cometer alguno de los siguientes delitos: robo, violación u homicidio. Se formaron dos grupos un grupo experimental y un grupo control.

Se exploró la efectividad de esta técnica psicofisiológica para detectar correctamente cuando la declaración de una persona es honesta o deshonesta y de esta manera poder comprobar si es una herramienta eficaz que contribuya en los procesos de evaluación de la credibilidad.

Por otra parte se analizó el perfil de personalidad de los participantes aplicando el Millon-III para tener una visión general sobre sus características de personalidad y elaborar hipótesis acerca de cómo estás pueden haber afectado el proceso de la entrevista del Análisis de Estrés de Voz.

\subsection{Procedimiento}

El procedimiento del estudio fue dividido en seis fases las cuales se desglosan en los siguientes párrafos.

Fase 1: Se aplicó a los participantes el Inventario Clínico Multiaxial de Millon III en aplicaciones grupales.

Fase 2: Los participantes entraron a una habitación cerrada donde un primer investigador le explicó la naturaleza y propósito de la investigación, después según el delito que haya cometido le dio a elegir al azar entre cuatro tarjetas diferentes (ver Anexo 1) las cuales categorizaron al participante en cualquiera de las siguientes categorías:

1) Grupo: Experimental

Condición: Decir la verdad

2) Grupo: Experimental 


\section{Condición: Mentir}

3) Grupo: control

Condición: Decir la verdad

4) Grupo: Control

Condición: Mentir

Fase 3: Los participantes del grupo experimental observaron un video relacionado al delito por el cual están presos: robo, violación u homicidio; para cada tipo de delito hay se utilizó un video relacionado al tipo de delito de esta manera los participantes que cometieron el delito de robo observaron un video donde dos hombres roban un coche, los que cometieron el delito de homicidio vieron un video donde un hombre dispara y asesina a otro y por último los que cometieron el delito de violación vieron un video donde una mujer es violada. Después de observar el video y dependiendo de la condición asignada por las tarjetas, el participante tenía que decir la verdad acerca de haber visto el video o de mentir acerca del mismo hecho.

Los participantes del grupo control no observaron ningún video y de la misma manera que el grupo experimental tuvo que decir la verdad acerca de haber visto el video o de mentir sobre el haber visto el mismo video.

Las instrucciones y seguimiento de este primer procedimiento fueron monitoreadas por el primer investigador, el cual dio las instrucciones a los participantes.

Fase 4: Una vez que las instrucciones queden claras un segundo investigador, designado como "entrevistador", aplicó una entrevista usando el software DVSA y aplicando un cuestionario de tipo Control Question Test (CQT) (ver Anexo 2). Este segundo investigador no tendrá información acerca de las instrucciones que el participante estará siguiendo. El interrogatorio fue calificado después de pasado un par de semanas para evitar el sesgo del entrevistador al calificar, de tal forma que el análisis sea solo con base en los resultados del software y los lineamientos para calificarlo y no dé la impresión de los investigadores durante la entrevista. Es importante hacer énfasis en que los evaluadores que participaron en esta tesis, fueron 
capacitados en el uso del DVSA y los procedimientos necesarios para evaluar la credibilidad del testimonio, ninguno de ellos es un experto en esta área.

Fase 5: En el siguiente paso de la investigación un tercer investigador cotejó las interpretaciones con las instrucciones que los participantes siguieron para verificar el número de aciertos y errores de los evaluadores.

Fase 6: Se aplicó a los participantes la prueba Millon de manera grupal, según el delito que hayan cometido. Posteriormente se calificaron e interpretaron las pruebas de cada uno de los participantes. 


\section{Capítulo 3. Resultados}

Con respecto a la aplicación del experimento del Análisis de Estrés de Voz se entrevistaron a un total de 23 sujetos, 11 sujetos en el grupo experimental y 12 sujetos en el grupo control, ocho sujetos habían cometido el delito de robo, ocho sujetos el delito de violación y siete sujetos el delito de homicidio (hubo una aplicación perdida debido a que la grabación no tenía la calidad necesaria para realizar el análisis usando el DVSA)

Se requirió la ayuda de cuatro evaluadores para realizar la evaluación de la credibilidad del testimonio usando el software DVSA, estos solo participaron en esta fase de la investigación, es necesario aclarar que ninguno de estos evaluadores tiene certificación en el manejo del DVSA ni son expertos en procesos de evaluación de credibilidad de testimonio, solo tienen seis meses de experiencia en el manejo del equipo y en el sistema de evaluación.

Se realizó la interpretación de las entrevistas realizadas durante el experimento, siguiendo el procedimiento estándar del FVAS (Forensic Voice Analysis Sistem), este procedimiento se describirá a continuación:

1) De cada entrevista se analizan las grabaciones y por medio del software de DVSA se seleccionan las respuestas a las preguntas y el software analiza el patrón de voz arrojando una gráfica por cada respuesta del individuo.

2) Se analizan las dos entrevistas realizadas por separado.

3) En cada entrevista se analiza el nivel de estrés de las preguntas Irrelevantes, Control y Relevantes. De acuerdo a los estándares de calificación delimitados para el DVSA.

4) Se espera que en una persona honesta el nivel de estrés de las preguntas Control sea mayor que en las preguntas Irrelevantes y Relevantes; de lo contrario se considera que es deshonesto.

5) Si la mayoría de las preguntas Relevantes tienen un nivel de estrés alto el entrevistado es considerado deshonesto. 
6) Se comparan los niveles de estrés de la primera y la segunda entrevista, se espera que en personas honestas el nivel de estrés disminuya en la segunda entrevista, de lo contrario se considera que la persona es deshonesta.

Los resultados de esta interpretación se dividían en Deshonestidad Indicada (DI), si se consideraba que el sujeto era deshonesto en sus respuestas; o No Deshonestidad Indicada (NDI), si se consideraba que el sujeto era honesto en sus respuestas. Terminada esta fase se cotejaba las interpretaciones de cada sujeto con las instrucciones que se les habían indicado, en esta fase se buscaba discernir el número de sujetos identificados correctamente como honestos o deshonestos y el número de sujetos identificados incorrectamente como honestos o deshonestos. Se creó una base de datos usando el Statistical Package for Social Sciences (SPSS) versión 17 donde se registró toda la información obtenida por los evaluadores así como todos los datos sociodemográficos de los participantes. Se realizó un análisis de frecuencias para conocer la distribución de los resultados del experimento y el porcentaje de identificados correcta e incorrectamente.

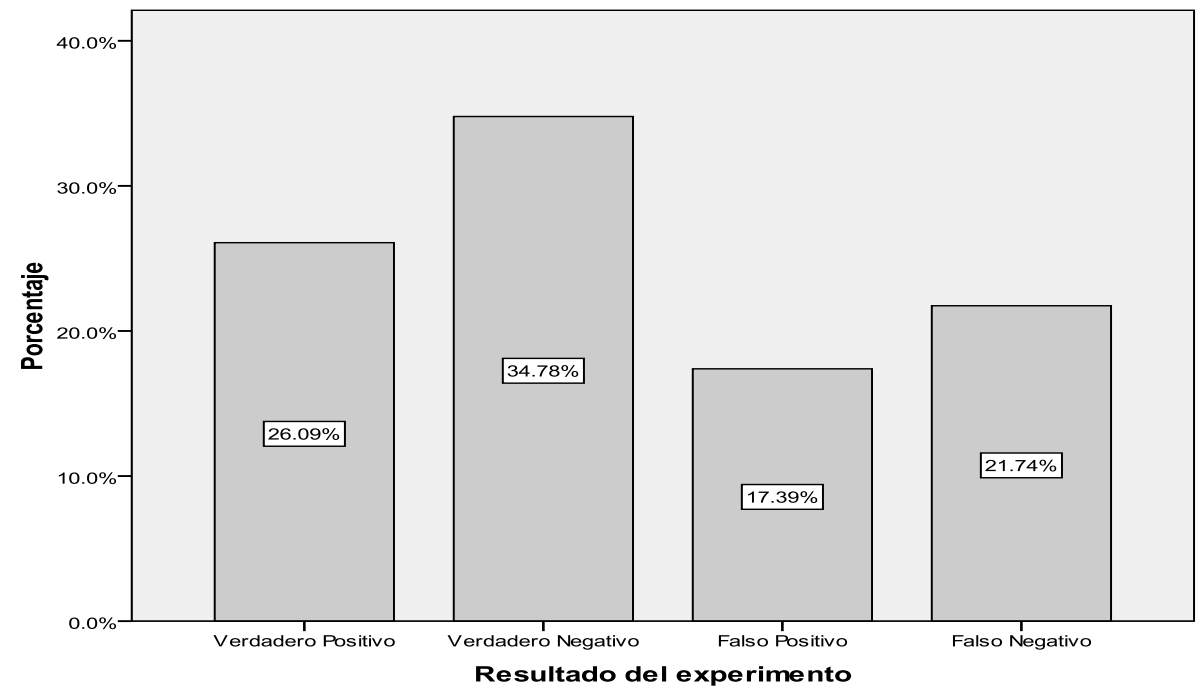

Figura 2: Resultados del experimento. 
Se puede observar en los resultados que el mayor porcentaje se encuentra en la condición "Verdadero Negativo", esto quiere decir que el 34.8\% de la población total fue catalogada correctamente como NDI (No Deshonestidad Indicada), esto quiere decir que estaban diciendo la verdad y fueron catalogados correctamente como No Deshonestos; otro $26.1 \%$ de la población fue catalogada correctamente como Deshonestos cuando estaban mintiendo, en otras palabras se les calificó como DI (Deshonestidad Indicada) y en efecto estas personas mintieron en sus respuestas; un $21.7 \%$ de la población fue catalogada incorrectamente como No Deshonestos, es decir, se les catalogo como NDI aun cuando estaban mintiendo en sus respuestas, por último $17.4 \%$ de la población fue identificada incorrectamente como Deshonestos, se consideró que eran deshonestos, que mintieron en sus respuestas, pero en realidad contestaron con la verdad.

Se observa que un $60.87 \%$ de la población fue identificada correctamente ya sea como honesto o deshonesto, mientras que un $39.13 \%$ de la población fue identificada incorrectamente como honesto o deshonesto.

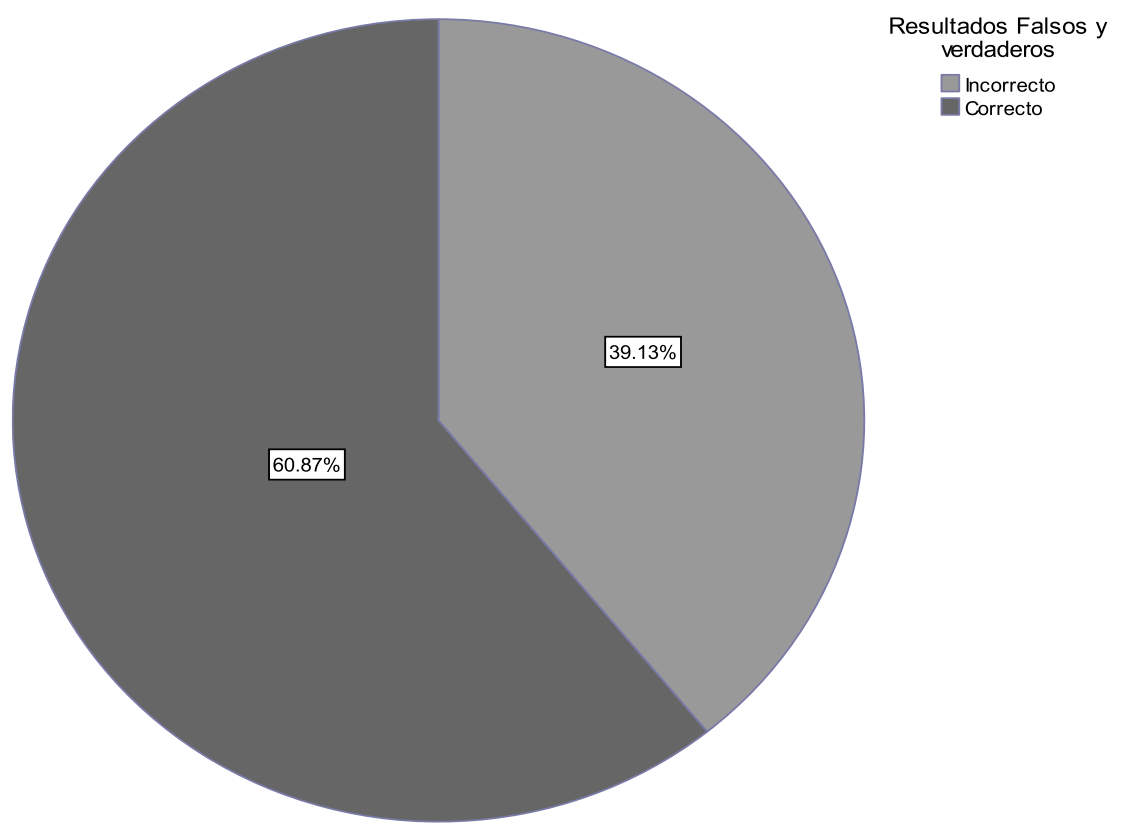

Figura 3: Porcentajes de identificados correctamente/incorrectamente. 
También se analizaron los índices de Sensibilidad y Especificidad del equipo de VSA. La sensibilidad es la habilidad del equipo para identificar correctamente el engaño, es el número de personas correctamente identificadas como deshonestas entre el número total de personas que estaba siendo deshonestas en la muestra, y multiplicado por 100. La especificidad es la habilidad para identificar correctamente a los sujetos que están siendo honestos en sus respuestas, es el número de personas identificadas correctamente como honestas sobre el número total de personas honestas en la muestra, y multiplicado por 100.

Para el equipo usado en esta investigación el índice de sensibilidad fue de $54.54 \%$, con respecto al índice de especificidad este fue $66.66 \%$, este índice es más alto que el de sensibilidad sin embargo es un resultado que está muy por debajo de un eficacia que podría considerarse moderada. Se podría concluir que el DVSA tiende a identificar a más personas que responden honestamente de manera correctamente que a identificar correctamente a personas que responden de manera deshonesta.

Con respecto a los resultados de la aplicación del MCMI-III, se hizo el análisis descriptivo de las medias para las diferentes escalas del Millon-III, en la siguiente tabla se enlistan las medias obtenidas para cada una de las 24 escalas del MCMI-III.

Tabla 4: Medias por tipos de delitos de las escalas del Millon-III

\begin{tabular}{crrrr}
\hline Escalas & M General & Homicidio & Violación & Robo \\
\hline Esquizoide & 50.43 & 58.50 & 39.33 & 47.40 \\
Evitativa & 44.00 & 44.67 & 43.33 & 43.60 \\
Depresiva & 42.14 & 44.83 & 38.33 & 41.20 \\
Dependiente & 39.14 & 37.50 & 51.00 & 34.00 \\
Histriónica & 45.50 & 50.17 & 36.33 & 45.40 \\
Narcisista & 72.21 & 76.17 & 60.33 & 74.60 \\
Antisocial & 52.64 & 43.67 & 61.00 & 58.40 \\
Agresiva (Sádica) & 56.64 & 46.83 & 65.33 & 63.20
\end{tabular}




\begin{tabular}{|c|c|c|c|c|}
\hline Compulsiva & 56.71 & 56.33 & 56.00 & 57.60 \\
\hline $\begin{array}{c}\text { Negativista (Pasivo- } \\
\text { Agresivo) }\end{array}$ & 50.71 & 50.83 & 51.00 & 50.40 \\
\hline Autodestructiva & 44.43 & 44.83 & 47.00 & 42.40 \\
\hline Esquizotípica & 41.21 & 43.17 & 45.00 & 36.60 \\
\hline Límite & 37.64 & 35.83 & 52.67 & 30.80 \\
\hline Paranoide & 66.57 & 63.17 & 71.33 & 67.80 \\
\hline Trastorno de Ansiedad & 51.14 & 54.50 & 59.67 & 42.00 \\
\hline Trastorno Somatomorfo & 38.00 & 36.50 & 40.67 & 38.20 \\
\hline Trastorno Bipolar & 51.29 & 51.50 & 65.33 & 42.60 \\
\hline Trastorno Distímico & 31.57 & 29.67 & 40.67 & 28.40 \\
\hline $\begin{array}{l}\text { Dependencia de } \\
\text { Alcohol }\end{array}$ & 58.21 & 51.67 & 69.67 & 59.20 \\
\hline $\begin{array}{l}\text { Dependencia de } \\
\text { Sustancias }\end{array}$ & 57.43 & 52.83 & 76.67 & 51.40 \\
\hline $\begin{array}{c}\text { Trastorno de Estrés } \\
\text { Postraumático }\end{array}$ & 37.71 & 36.17 & 39.67 & 38.40 \\
\hline $\begin{array}{l}\text { Trastorno del } \\
\text { Pensamiento }\end{array}$ & 33.00 & 32.00 & 44.33 & 27.40 \\
\hline Depresivo Mayor & 34.57 & 39.00 & 32.00 & 30.80 \\
\hline Trastorno Delirante & 63.07 & 59.83 & 57.33 & 70.40 \\
\hline Sinceridad & 60.57 & 59.17 & 72.00 & 55.40 \\
\hline Deseabilidad Social & 76.57 & 76.50 & 85.67 & 71.20 \\
\hline Devaluación & 48.71 & 50.67 & 49.67 & 45.80 \\
\hline
\end{tabular}

Se tomaron las escalas en las cuales la media es mayor a 60 en cada uno de los delitos, como se observa en la gráfica anterior las escalas con puntajes más altos son Narcisismo, Deseabilidad Social y Paranoide; los resultados se ilustran en la siguiente tabla. 
Tabla 5: Escalas con altos puntajes en las medias del MCMI-III

\begin{tabular}{cccc}
\hline Escalas & M General & Homicidio & Violación \\
\hline Narcisista & 69.93 & 71.69 & 68.12 \\
Deseabilidad Social & 68.35 & 69.14 & 67.53 \\
Paranoide & 67.74 & 69.06 & 66.38 \\
\hline
\end{tabular}

Para explorar si estos puntajes altos en las escalas de personalidad afectan los resultados en las interpretaciones del VSA se analizó individualmente a cada participante que haya tenido una puntuación $\mathrm{T}$ mayor a 60 en al menos una de las escalas ya mencionadas, pues son características que son encontradas en la mayoría de la muestra, la interpretación de la evaluación de credibilidad y si esta interpretación fue falsa o verdadera. Se esperaría según la literatura que las personas con puntuaciones altas el mayor número de escalas y con puntuaciones más altas en cada escala del Millon-III tengan resultados falsos, sin importar si son falsos positivos o falsos negativos.

Tabla 6: Resultado del Experimento y puntajes T de las Escalas altas de la muestra.

\begin{tabular}{lllll}
\hline Folio & Narcisista & Paranoide & $\begin{array}{l}\text { Deseabilidad } \\
\text { Social }\end{array}$ & $\begin{array}{l}\text { Resultado del } \\
\text { Experimento }\end{array}$ \\
\hline H01 & 60 & 77 & 53 & Falso Negativo \\
H02 & 78 & 20 & 85 & Falso Positivo \\
H03 & 70 & 66 & 80 & Falso Negativo \\
H04 & 70 & 68 & 80 & Verdadero \\
& & & & Positivo \\
H06 & 93 & 68 & 95 & Verdadero \\
& & & & Negativo \\
H07 & 86 & 80 & 66 & Verdadero \\
& & & & Negativo
\end{tabular}




\begin{tabular}{lllll} 
R01 & 70 & 60 & 71 & Verdadero \\
R04 & 90 & 68 & 85 & Positivo \\
R05 & 81 & 64 & 90 & Falso Negativo \\
R06 & 65 & 69 & 62 & Verdadero \\
R08 & 67 & 78 & 48 & Negativo \\
& & & & Falso Positivo \\
V03 & 53 & 79 & 91 & Verdadero \\
& & & & Positivo \\
V04 & 55 & 67 & 66 & Verdadero \\
V07 & 73 & 68 & 100 & Falso Positivo \\
& & & & Verdadero \\
\hline
\end{tabular}

No se encontró relación entre las puntuaciones obtenidas en las escalas: Narcisismo, Deseabilidad Social y Paranoide del Millon-III con los resultados de las evaluaciones de credibilidad, el porcentaje de sujetos evaluados correctamente, Verdaderos positivos o falsos, fue de $57.15 \%$ y el porcentaje de sujetos evaluados incorrectamente como Falsos positivos o Falsos Negativos fue del $42.85 \%$ Como se observa en la tabla anterior de los 14 participantes que tuvieron puntuaciones $\mathrm{T}$ por arriba de 60 en al menos una de las tres escalas identificadas como altas en la muestra, solo seis participantes, el $42.85 \%$ fueron identificados incorrectamente ya sea cómo Deshonestidad Indicada o No Deshonestidad Indicada; y el restante $57.15 \%$ de la muestra fueron identificados correctamente en las categorías ya mencionadas. 


\section{Capítulo 4. Discusión}

\subsection{Conclusiones}

A partir de los datos obtenidos en los resultados se puede llegar a las siguientes conclusiones generales, tomando en cuenta que los investigadores encargados de la interpretación de las entrevistas solo tiene una capacitación básica en el uso del equipo y en la técnica de interpretación del VSA, se identificó correctamente al $60.87 \%$ de la población total, lo cual aunque es un valor aparentemente bajo se debe considerar el nivel de experiencia de los evaluadores, por lo que probablemente este porcentaje sería más elevado si se recurriera a evaluadores con mayor experiencia y mejor capacitación en las técnicas del VSA. En segundo lugar, de la parte de la muestra que estaba siendo deshonesta solo se identificó correctamente $54.54 \%$, la sensibilidad del equipo, esta probabilidad no es mayor que lanzar una moneda, lo cual es un puntaje muy bajo para que el uso del equipo se considere eficaz a la hora de identificar correctamente a personas deshonestas, en cuanto a la identificación correcta de las personas honestas se obtuvo un mejor resultado, el índice de especificidad fue de $66.66 \%$, lo cual indica una eficacia moderada en el momento de identificar como honestas a personas que responden con la verdad o de manera honesta. Estos resultados son cercanos a los obtenidos por Hopkins et al. (2005), que examinaron grabaciones de 56 entrevistas de casos criminales; en esta investigación la precisión promedio de cinco programas diferentes de VSA para detectar el engaño fue de aproximadamente el 68\% y a los resultados obtenidos por Cestaro (1996) el cual encontró que otro equipo de VSA tiene una precisión de solo el $52 \%$.

Con lo referente a los resultados obtenidos en el perfil del Millon se encontró que para los tres tipos de delitos cometidos por los participantes los tres obtuvieron puntuaciones altas en las siguientes escalas del Millon: Narcisista, Deseabilidad Social y Paranoide, pues en las tres escalas el promedio de puntación T para cada tipo 
de delito es mayor a 60. Esto puede dar indicios de las características de personalidad de los internos del CE.RE.SO.,

La escala narcisista enlista las siguientes características para los sujetos con puntuaciones altas, se hacen notar por sus actitudes egoístas, experimentando placer simplemente por permanecer pasivos o centrados en sí mismos. Sobreestiman su propio valor, presumen de que los demás reconocerán sus particularidades. Mantienen un aire de autoconfianza arrogante; explotan a los demás aún sin intención o propósitos conscientes. Confianza en que las cosas saldrán bien lo cual les proporciona pocos incentivos para comprometerse.

En el índice para la calificación e interpretación en deseabilidad social se identifica el grado con que los resultados pueden encontrarse afectados por la inclinación de los sujetos a mostrarse socialmente atractivos, moralmente virtuosos o emocionalmente ajustados, mientras más alto sea el puntaje el sujeto trata de disimular sus aspectos psicológicos o dificultades personales.

Por último la escala paranoide explica que sujetos con puntajes altos tienden a mostrar desconfianza vigilante respecto de los demás y una áspera irritabilidad, así como una tendencia a la exasperación precipitada y colérica con los demás. Frecuentemente expresan un temor a la pérdida de independencia lo que los conduce a resistirse al control y a las influencias externas. Hay inmutabilidad de sus sentimientos y rigidez de sus pensamientos. (Millon, 2007).

Hasta este punto se han descrito las características de personalidad generales para la totalidad de los participantes de esta tesis, es decir, aunque las escalas del Millon-III para la muestra fueron la escala Narcisista, Paranoide y de Deseabilidad Social no quiere decir que todos los sujetos tengan puntuaciones altas en las tres o alguna de las tres escalas, probablemente existirán participantes que no tengas puntuaciones altas en una, dos o las tres escalas.

Basándonos solo en el análisis del porcentaje se puede afirmar que el hecho de tener un puntaje alto en alguna escala del Millon-III no afecta negativamente el resultado de la evaluación de la credibilidad usando el DVSA, no se tiende a evaluar incorrectamente a las personas evaluadas. Por lo tanto se puede concluir que un 
puntaje alto en alguna de las escalas Narcisismo, Paranoide o Deseabilidad Social del Millon-III, lo que puede significar un posible trastorno de personalidad, no afecta la eficacia del VSA para evaluar la credibilidad del Testimonio en internos del CE.RE.SO. de Tekax. No se encontró correlación entre las puntuaciones $\mathrm{T}$ de la muestra y la confiabilidad del VSA para identificar a los participantes como "No Deshonestos" o "Deshonestos". El hecho de que tengan puntuaciones altas en las tres escalas ya mencionadas del Millon-III no afecta el resultado de la interpretación del VSA.

Al final se puede concluir que los instrumentos de VSA son solo una herramienta más dentro de la gran gama de estrategias y técnicas usadas en los procesos de credibilidad de testimonio, y debido a la gran importancia y relevancia que existe en una evaluación de credibilidad de testimonio, así como la gran responsabilidad de decidir cuando una persona es honesta o deshonesta en un proceso legal, no se puede confiar por si solo en una sola herramienta este proceso debería estar acompañado de diferentes técnicas y estrategias para llegar a una conclusión satisfactoria.

\subsection{Limitaciones}

Entre las principales limitaciones del presente estudio está el tamaño de la población, la cual por la naturaleza de la misma es difícil de captar, pues muchos de los internos no desean participar, ya sea por desconfianza, o miedo de que el mismo procedimiento tenga alguna consecuencia en su situación legal, muchos de ellos decidían no participar aun cuando se les explicaba que el procedimiento tenía era por fines académicos y que no se relacionaba de ninguna forma con su proceso legal. Por estas razones solo se contó con un número pequeño de participantes, y de esta manera es difícil poder generalizar los descubrimientos del presente estudio en otros contextos o situaciones. 
Una limitación importante es la experiencia y capacitación de los evaluadores que realizaron la interpretación de las entrevistas de los sujetos participantes, pues cuentan con poco menos de seis meses de experiencia interpretando los resultados del VSA. Si los investigadores que interpretaron el VSA tuvieran una mejor preparación o mayor experiencia, probablemente se hubieran obtenido mejores resultados en cuanto a la certeza del uso del equipo para detectar a personas que responden de manera honesta o deshonesta. Claro que cabría la duda razonable de que mejores resultados podrían deberse a la pericia de los evaluadores más que a la confiabilidad del equipo DVSA. Por lo tanto, el uso de este tipo de instrumentos por evaluadores con poca experiencia, en procesos de evaluación de credibilidad de testimonio no aporta una certeza para poder identificar correctamente cuando una persona es Honesta o Deshonesta en sus respuestas. Hopkins, et al. (2005) observo que la precisión de la detección del engaño en cinco equipos diferentes de VSA aumenta un poco cuando las personas que usaron el equipo tenían más experiencia trabajando con los mismos. En futuros investigaciones o replicaciones de este experimento es recomendable contar con personas con una certificación en el uso del software DVSA y/o en la evaluación de la credibilidad por medio del análisis de estrés de voz, debido costo que conlleva obtener una licencia para el uso del software y a que son pocas las personas que tienen acceso al mismo o que tienen una certificación otra opción es contar con evaluadores con experiencia en interrogatorio o procesos de evaluación de control de confianza, por ejemplo técnicos en entrevista poligráfica.

También es importante considerar que por la naturaleza de las instrucciones, procedimientos del experimento, capacidades y nivel educativo de los participantes, muchos de estos tuvieron problemas para seguir las instrucciones, se realizaron 44 entrevistas en total para poder obtener la muestra de 23 participantes que se tomaron en cuenta en la presente tesis (los sujetos que siguieron correctamente las instrucciones dadas). En un futuro se podría aplicar el mismo procedimiento con una muestra de participantes con mayor nivel educativo para comparar los resultados, se esperaría que una población con mayor nivel educativo tenga mayor facilidad para seguir las instrucciones y de esta manera tener un mayor número de participantes, 
esta muestra muy probablemente debería ser de sujeto no internos en un centro penitenciario debido a la dificultad de encontrar internos con un nivel educativo alto. También se puede mejorar el diseño del experimento haciéndolo más sencillo para los participantes y evitar la muerte experimental.

Por supuesto un factor de vital importancia es que los sujetos que participaron en este estudio no tenían una motivación real para mentir, es decir, no había una razón de peso para que los sujetos se esforzarán en mentir, como por ejemplo el enfrentar una consecuencia legal por ser descubiertos al mentir, como pasa en procesos legales en la vida real. Debido a la naturaleza del experimento se debe mencionar que al no estar en una situación real de evaluación de credibilidad, se espera que el nivel de estrés de los sujetos durante la aplicación de la entrevista no sea lo suficientemente alto para que exista una diferencia significativa entre los sujetos a los que se les pedía que fueran honestos o deshonestos; para que exista un mayor nivel de estrés y cercanía con la realidad se debería usar un diseño experimental que se asemeje más a la realidad de una situación de evaluación de credibilidad de testimonio, o aplicar esta técnica en situaciones de evaluación de la credibilidad real donde exista un medio para corroborar la realidad objetiva, en otras palabras, saber con certeza en los hechos cuándo una persona está mintiendo o diciendo la verdad. 


\section{Referencias}

Aiken, L. (2003). Tests Psicológicos y Evaluación. México: Prentice-Hall

Baker Group International Inc (2008). Programa de certificación para operadores del sistema DVSA. Monterrey, N.L

Benavides, J. A. (2007). El Arte del Interrogatorio Científico. México: Imagen Grafica Aplicada.

Cestaro, V. \& Janniro, M. (1996). Effectiveness of detection deception examinations using the computer voice stress analyzer.

Damphouse, K. (s.f.). Voice Stress Analyisis: Only 15 percent of lies about drug use detected in field test. NIJ Journal, 259, 8-12

Damphouse, K., Pointon, L., Upchurch, D., Moore, R. (2007). Assessing the Validity of Voice Stress Analysis Tools in a Jail Setting.

Estudio sociodemográfico de los Centros de Readaptación Social de Yucatán (2010).

Garrido, E. Massip, J. (2000). La Evaluación del Testimonio en contextos Judiciales a partir de Indicadores Conductuales. Anuario de Psicología Jurídica, 93-131

Garrido, E., Masip, J. \& Herrero, M. C. (2006). Psicología Jurídica. Madrid: Pearson Godoy-Cervera, V., \& Dzib-Aguilar, P. (2010). Psicología del Testimonio: Técnicas, instrumentos y procedimientos. En E. García-López, Fundamentos de Psicología Jurídica y forense (págs. 493-521). México: OXFORD.

Hazelwood, R. (1.983). Entrevista con las Víctimas de Violación para obtener Información acerca del Comportamiento del Violador: La Clave de la Elaboración de Perfiles. FBI Law Enforcement Bulletin. Disponible en www.psicologiajuridica.org.

Heinz, O. (2000). El Dictamen sobre la Credibilidad de las Declaraciones de los Testigos. Anuario de Psicología Juridica. Pgs. 11-23

Hernández Fernández, E., \& Alonso Quecuty, D. M. (S.F). La detección de la mentira: Perspectiva científica vs legal. 
Hopkins, S., Benincasa, D.; Rattley, R.; Grieco, J. (2005). Evaluation of Voice Stress Analysis Technology. 38th Hawaii International Conference on System Sciences

Iacond, W. G., \& Patrick, C. J. (2006). Polygraph ("Lies detector") Testing: Current Status and Emerging Trends. En I. B. Weiner, \& A. K. Hess, The handbook of Forensic Psychology (pgs. 552-584). USA: John Wile \& Sons, Inc.

Ibabe Erostarbe, I. (2000). Psicología del Testimonio. País Vasco: ITXAROPENA

Jiménez Gómez, F. (2006). Evaluación psicológica forense. Matrimonio y procesos en la protección del menor. Salamanca: Amaru Ediciones.

Lemos Giraldez, S. (2005). Simulación, Engaño y Mentira. Revista del consejo General de Colegios Oficiales de Psicólogos. 26, 57-58

Lykken, D. T. (1981). A tremor in the blood. New York: Mc Graw-Hill.

Manzanero, A. (2008). Psicología del testimonio. Una aplicación de los estudios sobre la memoria. Madrid: Pirámide.

Marchiori, H. (1989). Psicología Criminal (6ta. Ed.) México: Porrúa

Martínez Selva, J.M (1995) Psicofisiología; Madrid: Editorial Síntesis.

Martínez Selva, J. M. (2005). La Psicología de la Mentira. México: Paidos.

Masip, J., Sporer, S.L., Garrido, E. y Herrero, C. (2005). The detection of deception with the reality monitoring approach: a review of the empirical evidence. Psychology, Crime \& Law, 11, 99-122.

Millon, T., Davis, R., \& Millon, C. (1997). MCMI-III Manual, 2 a ed. Minneapolis: National Computer Systems. 50, 444-445.

Millon, Th., Davis R. y Millon C. (2007). Millon Clinical Multiaxial Inventory-III, MCM-III. NCS Pearson, Inc. Minneapolis, Estados Unidos de América. Traducción alespañol (2007). Inventario Millon de Estilos de Personalidad. Madrid: TEA Ediciones, S.A.

Morris, C. G., Maisto, A. (2005) Psicología. México: Pearson Prentice Hall.

Palmatier, J. (s/f). The CVSA, Polygraph and Trustech/Verificator Voice Analysis Technologies. Tampa, Florida 
Pastor, M.C., Molto, J., Vila, J., \& Lang, P.J. (2003). Startle reflex modulation, affective ratings and autonomic reactivity in incarcerated Spanish psychopaths. Psychophysiology, 40, 34-938.

Raskin, D. (1994) Métodos Psicológicos en la Investigación y Pruebas Criminales. España: Biblioteca de Psicología.

Raskin, D. \& Hare, R., (1978). Psychopathy and Detection of Deception in a Prison Population. The Society for psychophysiological Research, Inc., 15 (2), 126-136

Reid, J. E. (1947). A revised questioning technique in lie detection test. Journals of Criminal Law, Criminology and Police Science. 37, 542-547.

Rosenfeld, J. P. (2002). Event-related potentials in the detection of deception, malingering, and false memories. En M. Kleiner (Ed.), Handbook of polygraph testing (pp. 265-286). Nueva York: Academic Press.

Ruby, C.L. y Brigham, J.C. (1997). The usefulness of the criteria-based content analysis technique in distinguishing between truthful and fabricated allegations: a critical review. Psychology, Public Policy, and Law, 3, 705-737.

Summers, W. G. (1939). Science can get the confession. Fordham Law Review, 5, 334-354.

Vázquez Mesquita, B. (2007). Manual de Psicología Forense. España: Editorial Síntesis.

Verschuere, B., Crombez, G. Koster, E. \& Uzieblo, K. (2006). Psychopathy and Physiological Detection of Concealed Information: A Review. Psycholica Belgica., 46, 99-116.

Vrij, A. (2000). Detecting lies and deceit: the psychology of lying and the implications for professional practice. Chichester: John Wiley \& Sons.

Vrij, A., Edward, K. y Bull, R. (2001). Stereotypical verbal and nonverbal responses while deceiving others. Personality and Social Psychology Bulleting, 27, 899909.

Vrij, A., Edward, K., Roberts, K. y Bull, R. (2000). Detecting deceit via analysis of verbal and nonverbal behaviour. Journal of Nonverbal Behaviour, 24, 239-263. 
Xianfeng, Liu (2005). Voice Stress Analisys: Detection of Deception. University of sheffield

Wylie, M. 2002. "Police Use of Voice Stress Analysis Generates Controversy." Newhouse News Service accessed at http://polygraph.com.au/pdf/police_use_of_voice_stress_analysis_generates_co

ntroversy. $\quad$ pdf 
Medición Psicofisiológica en Credibilidad de Testimonio 66

\section{Anexo A}

\section{Protocolo de Entrevista}




\section{Protocolo}

Nombre:

Delito:

Folio:

Grupo:

Condición Experimental:

Entrevistador

Control

\begin{tabular}{|c|c|c|c|l|}
\hline Orden & Aplic.1 & Aplic. 2 & Tipo Pre & Preguntas \\
\hline 1 & & & I & ¿Su primer nombre es \\
\hline 2 & & & ¿ & $\begin{array}{l}\text { ¿Teme fallar en alguna de las preguntas que le } \\
\text { voy hacer? }\end{array}$ \\
\hline 3 & & & R & ¿El video que vio fue de un homicidio? \\
\hline 4 & & & I & ¿Estamos en el mes de \\
\hline 5 & & & C & $\begin{array}{l}\text { ¿En alguna ocasión ha dicho una mentira grave a } \\
\text { una persona que confiaba plenamente en usted? }\end{array}$ \\
\hline 6 & & & R & $\begin{array}{l}\text { ¿Vio que un hombre le dispare a otro dentro } \\
\text { de un carro en el video? }\end{array}$ \\
\hline 7 & & & I & ¿El día de hoy es \\
\hline 8 & & & C & ¿Usted se considera una persona honesta? \\
\hline 9 & & & R & ¿El video que vio fue de una violación? \\
\hline 10 & & & i Usted habla español? \\
\hline 11 & & & R & $\begin{array}{l}\text { ¿Vio a una persona con una playera blanca en } \\
\text { el video? }\end{array}$ \\
\hline 12 & & & I & ¿Se encuentra usted de pie? \\
\hline 13 & & & & ¿El video que vio fue de un robo? \\
\hline 14 & & & I & $\begin{array}{l}\text { ¿En este momento tiene puesto una camisa de } \\
\text { color }\end{array}$ \\
\hline 15 & & & C & $\begin{array}{l}\text { ¿Teme haber fallado en alguna de las preguntas } \\
\text { que le dije por no decirme la verdad? }\end{array}$ \\
\hline 16 & & & R & $\begin{array}{l}\text { ¿En el video que observo, vio a dos hombres } \\
\text { robar un carro de color negro? }\end{array}$ \\
\hline 17 & & & I & ¿Se encuentra sentado? \\
\hline
\end{tabular}

Observaciones: 
Anexo B

\section{TARJETAS DE INSTRUCCIONES PARA EXPERIMENTO}


Delito: Homicidio

Grupo: Experimental

Condición: Decir la verdad

Folio:

\section{SIGUE LAS INSTRUCCIONES PASO A PASO:}

1) Observa cuidadosamente el video que está en la computadora. Presta atención pues se te harán preguntas acerca del video y tienes que contestar con la verdad a lo que se te pregunte.

2) Cuando el entrevistador te pregunte sobre el video que viste, tú contestarás diciendo la verdad, contestando a las preguntas según lo que viste en el video.

Ejemplo. Si tú viste un video de un homicidio; cuando el entrevistador te pregunte, tú contestarás diciendo la verdad:

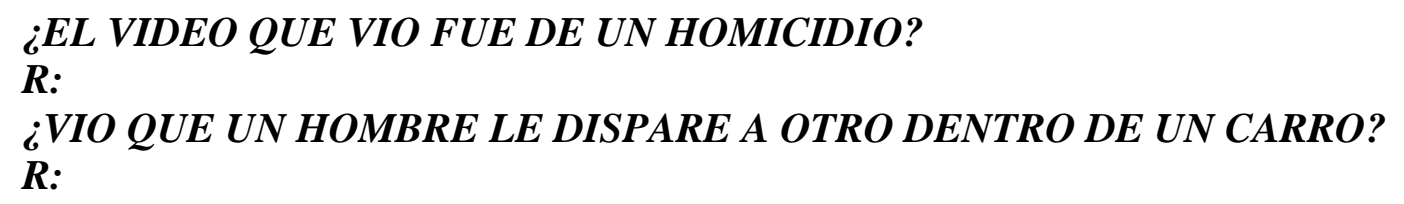

3) Entendiste las instrucciones.

4) Recuerda que el entrevistador no debe adivinar cuál es tu intención, y no debe saber las instrucciones que te acabo de dar. 
Tarjeta A2)

Delito: Homicidio

Grupo: Experimental

Condición: Mentir

Folio:

\section{SIGUE LAS INSTRUCCIONES PASO A PASO:}

1) Observa cuidadosamente el video que está en la computadora. Presta atención pues se te harán preguntas acerca del video y tienes que contestar mintiendo.

2) Cuando el entrevistador te pregunte sobre el video que viste, contéstale con una mentira. Niega que viste el video.

Ejemplo. Si tú viste un video de un homicidio; Cuando el entrevistador te pregunte, tú contestarás con una mentira:

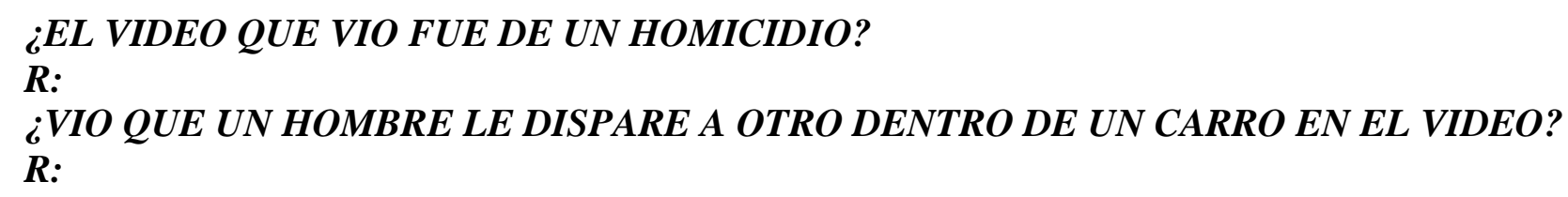

3) SOLO debes mentir a las preguntas relacionadas al video que viste, a las demás preguntas contestarás con la verdad. 4) Entendiste las instrucciones.

5) Recuerda que el entrevistador no debe adivinar cuál es tu intención y no debe saber las instrucciones que te acabo de dar. 
Delito: Homicidio

Grupo: Control

Condición: Decir la verdad

Folio:

SIGUE LAS INSTRUCCIONES PASO A PASO:

1) Permanece sentado.

2) Cuando el entrevistador te pregunte acerca de si viste algún video, tú contestarás con la verdad. Diciendo que no viste ningún video.

Ejemplo. Si tú no viste ningún video; cuando el entrevistador te pregunte, ¿Cómo vas a responder?

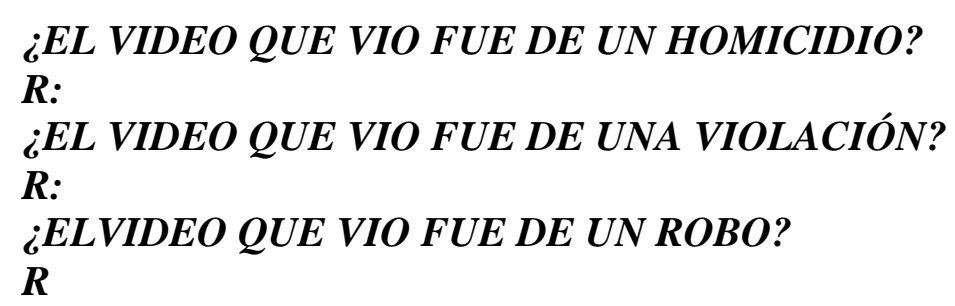

3) Entendiste las instrucciones.

4) Recuerda que el entrevistador no debe adivinar cuál es tu intención, y no debe saber las instrucciones que te acabo de dar. 
Delito: Homicidio

Grupo: Control

Condición: Mentir

Folio:

SIGUE LAS INSTRUCCIONES PASO A PASO:

1 Permanece sentado.

$\underline{2}$ Cuando el entrevistador te pregunte acerca de si viste algún video, tú contestarás mintiendo. Diciendo que viste algún video.

$\underline{\text { Ejemplo. }}$. Cuando el entrevistador te pregunte, vas a responder mintiendo diciendo que viste un video de robo y mentiras SOLO en las siguientes preguntas

\section{¿EL VIDEO QUE VIO FUE DE UN ROBO?}

R: ¿EN EL VIDEO QUE OBSERVO, VIO A DOS HOMBRES ROBAR UN CARRO DE COLOR NEGRO? $\boldsymbol{R}:$

$\underline{\mathbf{3}}$ Entendiste las instrucciones.

$\underline{4}$ Recuerda que el entrevistador no debe adivinar cuál es tu intención, y no debe saber las instrucciones que te acabo de dar. 
Tarjeta B1)

Delito: Violación

Grupo: Experimental

Condición: Decir la verdad

Folio:

\section{SIGUE LAS INSTRUCCIONES PASO A PASO:}

1 Observa cuidadosamente el video que está en la computadora. Presta atención pues se te harán preguntas acerca del video y tienes que contestar con la verdad a lo que se te pregunte.

$\underline{\mathbf{2}}$ Cuando el entrevistador te pregunte sobre el video que viste, tú contestarás diciendo la verdad, contestando a las preguntas según lo que viste en el video.

Ejemplo. Si tú viste un video de una violación; cuando el entrevistador te pregunte, tú contestarás diciendo la verdad:

\section{¿EL VIDEO QUE VIO FUE DE UNA VIOLACIÓN? \\ $R:$ ¿VIO QUE UNA PERSONA CON UNA PLAYERA BLANCA EN EL VIDEO? \\ R:}

$\underline{\mathbf{3}}$ Entendiste las instrucciones.

4 Recuerda que el entrevistador no debe adivinar cuál es tu intención, y no debe saber las instrucciones que te acabo de dar. 
Tarjeta B2)

Delito: Violación

Grupo: Experimental

Condición: Mentir

Folio:

\section{SIGUE LAS INSTRUCCIONES PASO A PASO:}

1 Observa cuidadosamente el video que está en la computadora. Presta atención pues se te harán preguntas acerca del video y tienes que contestar mintiendo.

$\underline{2}$ Cuando el entrevistador te pregunte sobre el video que viste, contéstale con una mentira. Niega que viste el video.

Ejemplo. Si tú viste un video de una violación; Cuando el entrevistador te pregunte, tú contestarás con una mentira:

\section{¿EL VIDEO QUE VIO FUE DE UNA VIOLACIÓN?}

$R:$

¿VIO A UNA PERSONA CON UNA PLAYERA BLANCA EN EL VIDEO?

R:

$\underline{3}$ SOLO debes mentir a las preguntas relacionadas al video que viste, a las demás preguntas contestarás con la verdad.

$\underline{4}$ Entendiste las instrucciones.

$\underline{\mathbf{5}}$ Recuerda que el entrevistador no debe adivinar cuál es tu intención y no debe saber las instrucciones que te acabo de dar. 


\section{Tarjeta B3)}

Delito: Violación

Grupo: Control

Condición: Decir la verdad

Folio:

SIGUE LAS INSTRUCCIONES PASO A PASO:

1 Permanece sentado.

$\underline{2}$ Cuando el entrevistador te pregunte acerca de si viste algún video, tú contestarás con la verdad. Diciendo que no viste ningún video.

Ejemplo. Si tú no viste ningún video; cuando el entrevistador te pregunte, ¿Cómo vas a responder?

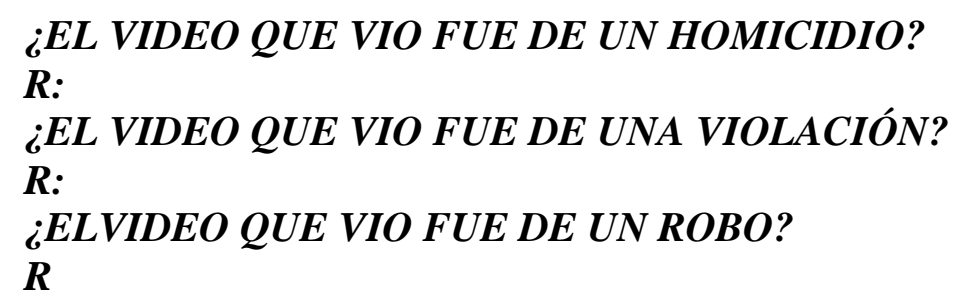

$\underline{\mathbf{3}}$ Entendiste las instrucciones.

$\underline{4}$ Recuerda que el entrevistador no debe adivinar cuál es tu intención, y no debe saber las instrucciones que te acabo de dar. 


\section{Tarjeta B4)}

Delito: Violación

Grupo: Control

Condición: Mentir

Folio:

\section{SIGUE LAS INSTRUCCIONES PASO A PASO:}

1 Permanece sentado.

$\underline{\mathbf{2}}$ Cuando el entrevistador te pregunte acerca de si viste algún video, tú contestarás mintiendo. Diciendo que viste algún video.

Ejemplo. Cuando el entrevistador te pregunte, vas a responder mintiendo diciendo que viste un video de un homicidio y mentiras SOLO en las siguientes preguntas

\section{¿EL VIDEO QUE VIO FUE DE UN HOMICIDIO? \\ R: ¿VIO QUE UN HOMBRE LE DISPARE A OTRO DENTRO DE UN CARRO EN EL VIDEO? R:}

$\underline{\mathbf{3}}$ Entendiste las instrucciones.

$\underline{4}$ Recuerda que el entrevistador no debe adivinar cuál es tu intención, y no debe saber las instrucciones que te acabo de dar. 
Tarjeta C1)

Delito: Robo

Grupo: Experimental

Condición: Decir la verdad

Folio:

SIGUE LAS INSTRUCCIONES PASO A PASO:

1 Observa cuidadosamente el video que está en la computadora. Presta atención pues se te harán preguntas acerca del video y tienes que contestar con la verdad a lo que se te pregunte.

$\underline{2}$ Cuando el entrevistador te pregunte sobre el video que viste, tú contestarás diciendo la verdad, contestando a las preguntas según lo que viste en el video.

Ejemplo. Si tú viste un video de un robo; cuando el entrevistador te pregunte, tú contestarás diciendo la verdad:

\section{¿EL VIDEO QUE VIO FUE DE UN ROBO? \\ R: ¿EN EL VIDEO QUE OBSERVO, VIO A DOS HOMBRES ROBAR UN CARRO DE COLOR NEGRO? R:}

$\underline{\mathbf{3}}$ Entendiste las instrucciones.

4 Recuerda que el entrevistador no debe adivinar cuál es tu intención, y no debe saber las instrucciones que te acabo de dar. 
Tarjeta C2)

Delito: Robo

Grupo: Experimental

Condición: Mentir

Folio:

\section{SIGUE LAS INSTRUCCIONES PASO A PASO:}

1 Observa cuidadosamente el video que está en la computadora. Presta atención pues se te harán preguntas acerca del video y tienes que contestar mintiendo.

$\underline{2}$ Cuando el entrevistador te pregunte sobre el video que viste, contéstale con una mentira. Niega que viste el video.

Ejemplo. Si tú viste un video de un robo; Cuando el entrevistador te pregunte, tú contestarás con una mentira:

\section{¿EL VIDEO QUE VIO FUE DE UN ROBO?}

R:

¿EN EL VIDEO QUE OBSERVO, VIO A DOS HOMBRES ROBAR UN CARRO DE COLOR NEGRO?

R:

$\underline{3}$ SOLO debes mentir a las preguntas relacionadas al video que viste, a las demás preguntas contestarás con la verdad.

$\underline{4}$ Entendiste las instrucciones.

$\underline{\mathbf{5}}$ Recuerda que el entrevistador no debe adivinar cuál es tu intención y no debe saber las instrucciones que te acabo de dar. 
Delito: Robo

Grupo: Control

Condición: Decir la verdad

Folio:

SIGUE LAS INSTRUCCIONES PASO A PASO:

1 Permanece sentado.

$\underline{2}$ Cuando el entrevistador te pregunte acerca de si viste algún video, tú contestarás con la verdad. Diciendo que no viste ningún video.

Ejemplo. Si tú no viste ningún video; cuando el entrevistador te pregunte, ¿Cómo vas a responder?

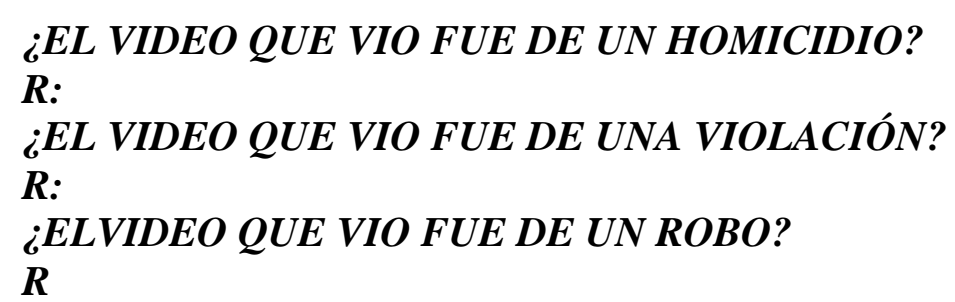

$\underline{\mathbf{3}}$ Entendiste las instrucciones.

$\underline{4}$ Recuerda que el entrevistador no debe adivinar cuál es tu intención, y no debe saber las instrucciones que te acabo de dar. 


\section{Tarjeta C4)}

Delito: Robo

Grupo: Control

Condición: Mentir

Folio:

\section{SIGUE LAS INSTRUCCIONES PASO A PASO:}

$\underline{1}$ Permanece sentado.

$\underline{\mathbf{2}}$ Cuando el entrevistador te pregunte acerca de si viste algún video, tú contestarás mintiendo. Diciendo que viste algún video.

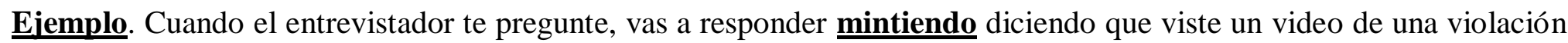
y mentiras SOLO en las siguientes preguntas:

\section{¿EL VIDEO QUE VIO FUE DE UNA VIOLACIÓN?}

R: ¿VIO A UNA PERSONA CON UNA PLAYERA BLANCA EN EL VIDEO? R:

$\underline{\mathbf{3}}$ Entendiste las instrucciones.

$\underline{4}$ Recuerda que el entrevistador no debe adivinar cuál es tu intención, y no debe saber las instrucciones que te acabo de dar. 